\title{
LA CONTRIBUCIÓN DE LAS REFORMAS PROTESTANTES EN LA APARICIÓN DE LOS DERECHOS Y LIBERTADES
}

\author{
The protestant reform's contribution on the appearance of \\ rights and freedoms
}

\author{
Cecilia Rosado-Villaverde \\ Profesora Contratada Doctora de Derecho Constitucional \\ Universidad Rey Juan Carlos
}

http://dx.doi.org/10.18543/ed-69(1)-2021pp241-277

Recibido: 15.04.2021

Aceptado: 18.06 .2021

\section{Resumen}

Nuestras actuales democracias son herederas de muchos de los fundamentos y nociones que se consolidaron durante los Estados liberales. Pero en la formación de estos estados influyeron diferentes aspectos que fueron trascendentales en el nacimiento de la organización política liberal. Uno de ellos fue el hecho o factor religioso. Se puede observar que las religiones extendidas en Europa y en Estados Unidos tuvieron cierta influencia, en mayor o menor medida, en los principios inspiradores que se reconocen en nuestros textos constitucionales. En este trabajo se pretende poner de relieve la relevancia que las Reformas protestantes tuvieron en el nacimiento de la libertad religiosa y de pensamiento, pero también en la propia concepción de las Declaraciones de derechos de finales del siglo XVIII.

\section{Palabras clave}

Tolerancia, Libertad religiosa, Protestantismo, derechos y libertades, individualismo. 


\begin{abstract}
Our current democracies are inheritors of many of the bases and notions that were consolidated during the liberal States. But the formation of these states was influenced by different aspects that were transcendental in the birth of the liberal political organization. One of them was the religious factor. It can be observed that the religions that spread across Europe and the United States have had a certain influence, to a greater or lesser extent, on the inspiring principles that are included in our constitutional texts. The aim of this work is to highlight the relevance that the Protestant Reforms had in the birth of religious freedom, but also in the very conception of the Bill of Rights of the late eighteenth century.
\end{abstract}

\title{
Keywords
}

Tolerance, Religious freedom, Protestantism, Rights and freedoms, individualism. 


\begin{abstract}
SUMARIO: I. INTRODUCCIÓN: LA INFLUENCIA DE LA RELIGIÓN EN EL NACIMIENTO DE LAS SOCIEDADES EUROPEAS MODERNAS. II. BREVE APUNTE SOBRE EL PAPEL DEL HECHO RELIGIOSO DURANTE LA EDAD MEDIA. III. LA REVOLUCIÓN PROTESTANTE Y SU INCIDENCIA EN EL MARCO POLÍTICO EUROPEO. IV. EL SINUOSO CAMINO DE LA FORMALIZACIÓN DE LOS DERECHOS EN ESTADOS UNIDOS Y SU RELACIÓN CON LAS REFORMAS PROTESTANTES. V. CONClusiones. Bibliografía.
\end{abstract}

«La Religión, entonces, de cada hombre debe dejarse a la convicción y conciencia de cada hombre; y todo hombre tiene el derecho de ejercerlo según lo dicten estos. Este derecho es por naturaleza un derecho inalienable. Es inalienable, porque las opiniones de los hombres, que dependen sólo de la evidencia contemplada por sus propias mentes, no pueden seguir los dictados de otros hombres: es inalienable también, porque lo que aquí es un derecho para con los hombres, es un deber para con el Creador». (Madison, Memorial and Remonstrance against Religious Assessments, $1785)^{1}$.

\title{
I. INTRODUCCIÓN: LA INFLUENCIA DE LA RELIGIÓN EN EL NACIMIENTO DE LAS SOCIEDADES EUROPEAS MODERNAS
}

El siglo XVIII se conoce constitucionalmente como el siglo de las revoluciones liberales y el momento del cambio del Antiguo Régimen al inicio de los futuros estados democráticos. Uno de los hitos más importantes de esta transformación es el nacimiento de los derechos y libertades y su plasmación en declaraciones. Eso no significa que en los periodos anteriores no hubiera derechos, todo lo contrario, existen numerosos antecedentes de reconocimiento de éstos. Así, se pueden citar, entre otros ejemplos, el Fuero de León (1017-1020) (González Díez y González Hernández, 2018) o la Carta Magna de 1215 (Satústregui Gil-Delgado, 2009, 244-262). Ambos textos hablaban ya del respeto a la propiedad privada de los nobles o la protección de los súbditos. Pero, y sin obviar la gran importancia de todos los documentos precedentes sobre esta cuestión, en estas líneas se busca analizar algunos de los eventos más inmediatos que marcaron la filosofía que hay detrás de la configuración de los derechos entre el siglo XVII y el siglo XVIII, que se convirtieron en piedra angular de los estados liberales y de su progreso hacia los estados democráticos actuales.

\footnotetext{
${ }^{1}$ Consultado en https://founders.archives.gov/documents/Madison/01-08-02-0163
} 
La dificultad para abarcar en su totalidad los elementos que influyeron en la aparición de uno de los hechos más destacados de nuestras sociedades contemporáneas es claro cuando se ahonda en este asunto. En unas pocas páginas resulta muy difícil tratar todos los aspectos que afectaron a la aparición y consolidación de los derechos y, por ello, el propósito de este artículo es esbozar alguno de ellos para poder entender cómo la relación de aspectos filosóficos, teológicos, políticos, sociológicos, educativos, bélicos, institucionales o históricos ha influido en su conformación. Tampoco es el objetivo de estas líneas recoger fielmente un tránsito histórico completo de lo sucedido durante varios siglos.

La aparición de las Reformas protestantes durante el siglo XVI marcó profundamente el devenir de la historia política y social de Europa y de los Estados Unidos de América y fue esencial para la creación y consolidación de los derechos del siglo XVIII. Los beneficios y aportaciones a nuestras democracias son palpables y evidentes, aunque no hay que olvidar que todo hecho también tiene su cara B. No se trata de ensalzar este movimiento, ni de desdeñar otras evoluciones religiosas. Tampoco pretende ser este un trabajo teológico. Se trata de entender, desde una visión constitucional, cuál fue la contribución de las Reformas protestantes en el impulso de la creación y consolidación de nuestros derechos y libertades. En este sentido, lo que trato de explicar es la revolución que produjo la aparición del protestantismo para la Europa medieval y su ruptura con la Iglesia Católica y las consecuencias que todo ello trajo en el desarrollo de los Estados liberales.

El protestantismo, siguiendo el halo que había comenzado el humanismo a finales del siglo XV, desarrolló su doctrina en torno a la idea de tolerancia. Dicha reflexión no era nueva, ya en los albores del cristianismo se hablaba de ella. Pero el gran triunfo de este nuevo movimiento religioso supuso que el concepto de tolerancia no desapareciera más del debate religioso y constitucional $^{2}$ y derivara en el nacimiento de algunas de las primeras libertades: la de conciencia, la religiosa y la ideológica. Por supuesto, la consolidación de la tolerancia y su importancia en el debate constitucional no se debió únicamente a las revoluciones protestantes. Sin duda alguna, la Ilustración fue sustancial en cuanto a la conceptualización de la tolerancia. Una de las obras más importantes en esta área fue Los Escritos sobre la tolerancia, de John Locke (Locke, 1999), cuya aportación ha sido clave en el desarrollo y consolidación de la tolerancia y de los derechos y libertades.

A lo largo de la historia del cristianismo, las rupturas han sido constantes y nuevos cambios hicieron evolucionar las doctrinas religiosas. La aparición del protestantismo no terminó con dichas rupturas, aunque el Cisma del siglo

${ }^{2}$ Aunque siempre existan regímenes, religiones y ciclos históricos en los que la oscuridad total se posara en la tolerancia y en la humanidad. 
XVI destacó por su gran expansión y afectación a otros ámbitos de la vida de los Estados. Pero años, décadas y siglos después, el cristianismo ha seguido evolucionando y amoldándose a la sociedad con la que compartía su presente. De hecho, la propia doctrina protestante ha cambiado desde su nacimiento, en algunos casos abanderando la insignia de libertad y tolerancia, pero en otros casos no ha sido así ya que la historia de numerosas religiones está afectada por la existencia de movimientos más conservadores e incluso, intransigentes, y el protestantismo no se libra de esta circunstancia (Filoramo, 2001, 459; Flavel, 2018; Ortega y Medina, 2013) ${ }^{3}$.

En los Estados Unidos de América, la libertad religiosa aparece regulada en sus declaraciones en los primeros artículos. De ahí que este trabajo, aunque busque hablar de los derechos y libertades de manera amplia, en algunas ocasiones se centre más específicamente en esta libertad. No es un análisis exhaustivo de ella pero sí quiero explicar cómo a través de la evolución del hecho religioso y más adelante de la libertad religiosa, podemos observar algunas de las características que comparten todos los derechos. Además, la libertad religiosa se reconoce en muchas ocasiones como la puerta de entrada al reconocimiento de otros derechos y libertades (Souto Paz y Souto Galván, 2010, 29-40).

Para comprender la teoría del Estado es significativo entender cómo han funcionado las instituciones religiosas ya que han sido parte, durante muchos siglos, del juego político de los países. Así, en muchas ocasiones la identidad del poder político y eclesiástico ha sido prácticamente total. La separación de la Iglesia y el Estado tardó mucho en aparecer y aunque algunos de los elementos de dicha separación se encuentran en las reformas protestantes, también es cierto que el pensamiento ilustrado y la argumentación liberal fueron los protagonistas definitivos de tal separación, necesaria para avanzar hacia estados más democráticos.

\section{BREVE APUNTE SOBRE EL PAPEL DEL HECHO RELIGIOSO DURANTE LA EDAD MEDIA}

El cristianismo, que había sido duramente perseguido por el Imperio Romano desde su aparición, cambió su situación cuando el Emperador

${ }^{3}$ Es el caso del puritanismo a mitad del siglo XVIII en las trece colonias Americanas. El puritanismo deriva del Calvinismo y nace en Inglaterra. Resulta sumamente complicado y une de manera consciente la religión con la política. Una de las características de este movimiento religioso es «una purificación de la religión cristiana más radical que la llevada a cabo por el anglicanismo, eliminando todo residuo papal, no sólo parte de él»; entienden que en el parlamento, órgano que representa a la soberanía nacional, Dios también manifiesta su voluntad; reclaman la autonomía de la comunidad cristiana en cada localidad con respecto al poder político y al poder religioso. 
Constantino (306-337) se convirtió a este credo. Con el Emperador Teodosio (379-395), se transformó en la religión oficial del Estado ostentando desde entonces el monopolio de la fe $\mathrm{f}^{4}$. En los años anteriores a este reconocimiento, durante su persecución, los cristianos defendieron y reivindicaron la libertad de conciencia (Mitre, 2010, 9) ${ }^{5}$. Es decir, ya en los primeros tiempos del cristianismo la libertad de conciencia fue un punto básico de su teología y filosofía.

Transformarse en la iglesia oficial también supuso que el nexo con el poder político se volviera profundo y sólido (Teja, 2006, 63-81). Tanto el Derecho Civil como el Derecho Penal de los años del Imperio de Teodosio estaban influidos por la moral cristiana. Además, el sistema jerárquico heredado de los romanos por la Iglesia Católica comienza ahora a delinearse. El emperador es, a su vez, el «obispo externo» que forma parte de la organización eclesiástica y su misión es defender la unidad y la ortodoxia del cristianismo (Filoramo, Massenzio, Raveri y Scarpi, 2012,162) ${ }^{6}$. Y los obispos ${ }^{7}$ empiezan también a ocuparse de funciones civiles (Filoramo, 2001, 104). De esta forma, lo que se produce es la mutua dependencia entre Iglesia y Estado.

La separación del Imperio romano en el Imperio bizantino de Oriente y en la fragmentación bárbara del Imperio romano de Occidente, trae consigo las primeras diferencias oficiales dentro del cristianismo, que finalmente culminarían en el Cisma de Oriente (1054) cuando se produjo la fragmentación en dos Iglesias. Estos movimientos dentro del cristianismo tienen directa relación con la estrategia política que se da en cada momento del periplo histórico. Así como cambian los centros de poder, la sociedad o el sistema económico, también la religión va adaptándose. Por ello la historia del cristianismo no transcurre aislada de la política ni de la sociedad que se da entre los siglos v y XV en Europa, más bien es parte inseparable de ella.

El hecho religioso tuvo un papel muy importante en Europa durante la Edad Media. Su relación con el poder político en cada una de las etapas medievales

${ }^{4}$ Lo hace a través del Edicto de Tesalónica en el año 380.

${ }_{5}$ En un primer momento el cristianismo no fue perseguido especialmente por el Imperio romano, que lo veía como una secta del judaísmo y, por tanto, permitía su existencia. Pero el objetivo de convertirse en una religión universal, su mensaje teológico y político, y la expansión que comenzó a mostrar, provocó que a mediados del siglo III comenzara la persecución de sus seguidores. Con el Edicto de Milán del año 313, Constantino estableció la libertad de cultos en el Imperio.

${ }^{6}$ La palabra ortodoxia deriva del griego «orthos» y significa justo, recto, y «doxa», que significa opinión o doctrina. En el cristianismo se consolida el concepto de ortodoxia «como un conjunto de ideas, garantizadas por la fe en la tradición, que considera vana verborrea las opiniones de los adversarios».

7 Estos obispos provenían del estamento de la nobleza, que a su vez era el estamento del cual salían las personas que ocupaban las altas magistraturas en el Imperio. 
y su influencia cultural y social fue palpable en países como Francia, los territorios germanos (después unidos en el Sacro Imperio) e incluso en Gran Bretaña (Harding, 1993, 50-67). Pero además, una de las características básicas de la Iglesia fue su actuación, desde la Alta Edad Media, como «la nueva fuerza unitaria» (Mitre, 2010, 37). Frente a la diseminación del poder político entre reyes y señores feudales, la Iglesia mantuvo una única organización que se extendía por toda Europa, donde la jerarquía del poder se establecía de manera clara y eficaz con el Obispo de Roma a la cabeza, el Papa. Además, desde esta época poseía un Derecho eclesiástico unificado y algunos de sus miembros eran también señores feudales que administraban las tierras. Por lo que respecta a su estrategia política, sobre todo durante la alta Edad Media, la Iglesia defendió, en la mayoría de los casos, la autoridad y legitimidad del Rey frente a los señores feudales. Aunque esta maniobra dio sus frutos, es verdad que no siempre tuvo el éxito pretendido 8 .

Pero es sin duda durante los últimos cinco siglos de la Edad Media que las cosas en el cristianismo comenzaron a cambiar. El Gran Cisma, que separó definitivamente la Iglesia católica y la Iglesia ortodoxa fue el punto de inflexión para la religión en este momento histórico. Varios aspectos de esta separación fueron muy relevantes. En primer lugar, se produjeron distinciones tanto en la ortodoxia como en su propia organización institucional. Por un lado, en Oriente se consolidó una identificación entre Iglesia-Estado, mientras que en Occidente se abogó por una unión de ambas, sin olvidar que el poder temporal no podía ser igual que el poder espiritual. En segundo término, esta separación supuso el primer gran golpe a la unidad cristiana. Anteriormente ya había habido diferencias en el seno de la Iglesia sobre cómo interpretar la palabra de Jesús y sobre cómo organizarse, pero esta fue la primera gran separación que vivió la fe cristiana. No sería la última (Filoramo, 2001, 45) ${ }^{9}$. Sin embargo, no

${ }^{8}$ De hecho el siglo x es conocido como el siglo de Hierro en la Iglesia de Occidente. La autoridad imperial de Roma dejó de apoyar a la Sede Apostólica y supuso que ésta se viera sometida a los distintos señores feudales y príncipes que intervenían de forma tiránica en la elección de los obispos de Roma. En siglo y medio fueron elegidos más de una treintena de Papas impuestos por las casas nobiliarias.

9 Es el caso de la crisis arriana producida en el siglo IV. El arrianismo nace en Alejandría, cuando el monje Arrio en el año 320 d. C, aproximadamente, comienza a difundir, tomando como punto de origen la doctrina trinitaria, que Padre, Hijo y Espíritu Santo son diferentes entre sí y además, existe una subordinación en orden descendente (el Hijo no es coetáneo del Padre, ni fue engendrado por éste). Este movimiento tuvo un importante número de seguidores provocando numerosas controversias dentro de la Iglesia. El obispo de Alejandría, Alejandro, por orden del emperador Constantino, convocó el concilio de Nicea en el año 325. En dicha reunión se condenó a Arrio y se decretó el principio trinitario en el que «Cristo es Hijo de Dios, y ha sido engendrado de la sustancia del Padre, así que es consustancial a él». 
volvería a sufrir una ruptura de estas dimensiones, o de dimensiones mayores, hasta el siglo XVI. La tercera cuestión es que dicha ruptura marcó los límites de ambas Iglesias (Filoramo, 2001, 103) ${ }^{10}$.

En cuanto a su relación con el poder político, los reyes respetaban el orden creado por Dios, y además no existía una separación entre Iglesia y Estado. No obstante, se produjeron numerosos enfrentamientos entre los reyes y el Papa, que perdió parte de su poder político en los conflictos bajomedievales (Aguilera Barchet, 2011, 130-182; Mitre, 2010, 149-150) ${ }^{11}$. De hecho, el papado se enfrentó con algunos monarcas en una lucha de poder que trajo consigo que a principios del siglo XIV coexistieran tres papas durante la confrontación de los Cien años, apoyados políticamente por las monarquías medievales (Mitre, 2010, 307-314) ${ }^{12}$. Aun así, el catolicismo se asienta como la única religión oficial de muchos países europeos, como en el Sacro Imperio Romano Germánico. En la política interna de la Iglesia católica, hay que mencionar que a partir del siglo XIII comienza el diseño de un

${ }^{10}$ Así, la de Occidente o católica se fundamenta sobre una estructura institucional muy bien organizada que sigue los mandatos del principio de jerarquía, en contraste con la Iglesia ortodoxa. Fue el pontífice Gregorio VII el que impulsó la formación de esta estructura eclesiástica, centralista y leal al Obispado de Roma, que es superior tanto a nivel teocrático como sobre los poderes temporales. Así, la Iglesia católica se coloca en el mundo divino y en el mundo político terrenal.

${ }_{11}$ Por ejemplo, El monarca Enrique IV, que pugnaba por el poder real del Imperio y que no estaba de acuerdo con la supremacía pontificia, comenzó una cruenta batalla con Gregorio VII. Esta lucha que duró más de una década es una muestra de las relaciones complicadas que tenían algunos de los reyes con el Papado a nivel político. La paz de esta batalla llegó con los sucesores de Enrique IV y Gregorio VII, aunque no fue suficiente para terminar definitivamente con el conflicto. El Papa Calixto II y Enrique V firmaron la paz en el Concordato de Worms en 1122. Además, estos acontecimientos están íntimamente relacionados con la deriva política que siglos después tomarán las Reformas Protestantes en los territorios germánicos.

12 Asimismo, las pugnas entre el papado y los monarcas siguieron Las fuerzas se mantenían bastante equilibradas (Francia, Escocia, Aragón, Castilla y la Italia meridional apoyaban a Clemente VII mientras que a Urbano VI le apoyaban Inglaterra, Italia central y septentrional, Alemania, Flandes y algo más tarde, Portugal) y, por tanto, la solución no fue sencilla, pero se planteó que lo mejor sería convocar un nuevo Concilio. El planteamiento de que el Concilio sería la solución al conflicto fue tomando fuerza a través de diferentes teóricos, como Marsilio de Padua, y monarcas cansados de la situación. Estos autores argumentaron, sin despreciar el poder del pontífice, que el Concilio estuviera por encima de cualquier miembro eclesiástico. Este razonamiento venía de otro más profundo que mantenía que un Papa se podía equivocar mientras que la Iglesia romana representada en su conjunto por sus miembros a través de un Concilio no se equivocaría. En 1413 se convocó el nuevo Concilio que finalizaría con la situación bicéfala de la Iglesia -e incluso tricéfala-. Finalmente, en noviembre de 1417 se eligió al Papa Martín V para toda la comunidad católica. 
cambio cuyo objetivo fue afianzar una «auténtica vida apostólica» basada en los propósitos de mendicidad y en la vuelta a la predicación del Evangelio. Todo ello buscaba acallar las voces críticas que se alzaban desde hacía décadas en su seno y que podían crear elementos que distorsionaran la unidad religiosa que tan importante era dentro las estrategias políticas medievales (Duby, 2007, 13-39).

Aunque el Cisma de Oriente y Occidente había llegado a su fin, sus consecuencias negativas en la sociedad europea fueron significativas y no desaparecieron con el Concilio que eligió al nuevo Papa. Los abusos eclesiásticos a la población, su situación privilegiada como señores feudales, sus continuas luchas de poder con los monarcas, sus intereses en la política de los reinos y la búsqueda constante de recursos económicos son algunos de los elementos que actuaron como caldo de cultivo para lo que vendría al inicio del siglo XVI (Wickham, 2017, 161-191).

En el ínterin entre el paso de la Edad Media a la Edad moderna (S. XV), se produjeron decisivas transformaciones ${ }^{13}$ que más adelante se vieron cristalizadas en los Estados modernos que aparecieron tras el fin del largo período medieval. Una de ellas se produjo en el ámbito filosófico. Apareció el humanismo que representaba la rama del pensamiento que situaba al hombre en el centro. Esta era, y es, una teoría antropocéntrica donde el ser humano es la medida de todas las $\operatorname{cosas}^{14}$, y se basa en la razón, la experiencia y la observación. Esta doctrina dejó de seguir la teoría principal medieval donde Dios era el centro de todo lo que sucedía. Reconoció virtudes humanas como el prestigio, el poder o la gloria que no eran admitidos como tales por la Iglesia

${ }^{13}$ Dos de estas transformaciones estaban relacionadas de manera directa con las reformas protestantes. En primer término, el campo científico. Aparecieron nuevos inventos, como la imprenta en 1440 (Johannes Gutenberg) que supuso un profundo cambio cultural en la sociedad. Esta herramienta trajo consigo la apertura y la expansión de los textos al gran público y el cambio en los hábitos de lectura (Vázquez Medel, 2010, 15-33), se empezaron a producir libros en lenguas distintas al latín y nuevas obras comenzaron a escribirse y a duplicarse. Uno de los libros más reproducidos fue la Biblia. Así, muchos creyentes conocieron la palabra de Cristo no sólo a través de los curas y eclesiásticos, sino directamente a través de las escrituras sagradas. Cuando el conocimiento es directo, no sólo a través de la palabra de otro, se puede ampliar el campo del entendimiento y se puede razonar y profundizar sobre lo leído.

${ }^{14}$ Uno de los pensadores humanistas más destacado fue Erasmo de Rotterdam (14661536). Sus críticas a la teología y su aversión al poder autoritario fueron dos rasgos muy característicos de él. Sus obras fueron esenciales para el pensamiento intelectual europeo y base para las reformas protestantes, aunque él nunca se definió claramente en ninguna de las posturas cristianas que convivieron durante su vida. Nunca fue protestante y aunque criticó a la Iglesia católica también estaba en desacuerdo con alguna de las ideas de las nuevas confesiones. Siempre buscó un equilibro entre el cristianismo protestante y el católico. 
y por su doctrina de Dios como centro de todo. Puso de manifiesto que la fe ya no era patrimonio de Dios sino que pertenecía al hombre. La idea de tolerancia subyacía en todas sus hipótesis porque la confianza se la otorgaba al hombre, que era capaz de decidir sobre su vida y de resolver sus propios problemas y dificultades. Le cedió al individuo la capacidad de actuar de manera autónoma y, por tanto, a no vivir enraizado en las nociones y supersticiones religiosas impuestas por el orden establecido. En cuestiones de fe, el hombre también se convirtió en un ser autónomo para decidir. Además, la aparición de esta doctrina filosófica, que nace en Italia a partir de la segunda mitad del siglo $\mathrm{XIV}^{15}$, afectó a otros espacios como la educación o la organización social, más allá de la argumentación teórica.

Las ideas humanistas pusieron de relieve que la sociedad debía buscar, en primer término, el bienestar del ser humano y la organización de la sociedad tenía que centrarse en este punto. En la educación, el modelo empezó a cambiar desde una educación ligada a la religión y a la filosofía teocéntrica hacia una enseñanza más centrada en el individualismo de los alumnos y en una formación más práctica, para que luego la pudieran aplicar a su vida civil y política. ${ }^{16}$. Además, también se apoyó en la cultura y la sociedad griega y romana que fueron el modelo a seguir. La aparición del humanismo fue fundamental en la evolución de la separación entre la fe y la razón, es decir, la separación entre el catolicismo y la filosofía y la ciencia. Dicha rama del conocimiento fue una de las claves que plantaron la semilla de las Reformas protestantes del siglo XVI.

\section{LA REVOLUCIÓN PROTESTANTE Y SU INCIDENCIA EN EL MARCO POLÍTICO EUROPEO}

Con la caída de Constantinopla a manos de los turcos otomanos (1453) aparece un nuevo modelo organizativo del poder que se centraliza en los monarcas, que pasan a dirigir Estados absolutistas. Entramos en el periodo

${ }^{15}$ El humanismo nace en Italia junto con el Renacimiento que se extenderá durante los siglos XV y XVI por Europea. Este Renacimiento, al igual que el humanismo, posan su mirada en la cultura clásica griega y romana que tomarán como modelos de perfección. El Renacimiento se centrará en el arte y la literatura, mientras el humanismo lo hará en la educación, la cultura, la ciencia, la filosofía y la política. Estos dos movimientos no serán compartimentos estancos sino que se retroalimentarán.

${ }_{16}$ El humanismo nace en Italia junto con el Renacimiento que se extenderá durante los siglos XV y XVI por Europea. Este Renacimiento, al igual que el humanismo, posan su mirada en la cultura clásica griega y romana que tomarán como modelos de perfección. El Renacimiento se centrará en el arte y la literatura, mientras el humanismo lo hará en la educación, la cultura, la ciencia, la filosofía y la política. Estos dos movimientos no serán compartimentos estancos sino que se retroalimentarán. 
conocido como la Edad moderna que se extiende durante los siglos XVI, XVII y XVIII.

La Iglesia católica vivía un momento de crisis que continuaba desde tiempo atrás. A nivel institucional esta crisis era más que evidente, con numerosos Concilios celebrados durante el siglo XV que no parecían conseguir el objetivo de reformarla. El último Concilio Lateranense V (15121517) dejó al descubierto la difícil tarea de unir otra vez la institución y la doctrina católica y puso en evidencia la ruptura entre el alto y el bajo Clero, debido a los abusos y la corrupción de gran parte de los primeros (Filoramo, 2001, 474-475). Pero a nivel espiritual, también existían grandes diferencias doctrinales dentro de la institución eclesiástica con respecto a las condiciones de la fe. Se estaba predicando con la vuelta al cristianismo primitivo. Todo ello venía de los antecedentes medievales del agustinismo ${ }^{17}$ que propugnaba por el cumplimiento de las consignas de pobreza, obediencia y austeridad, y de la vía mística. La irrupción del humanismo ${ }^{18}$ en la cultura, la sociedad y educación, también afectó a la doctrina católica.

En el parámetro político, el gran poder en la Tierra del Papa trajo consecuencias adversas en la relación con algunos de los reyes que miraban con descontento la concentración de la influencia del Obispo de Roma en los asuntos que iban más allá del plano de la fe. La Iglesia actuaba como un auténtico Estado y movía sus fichas en el tablero de ajedrez del poder europeo. La corrupción que existía dentro de la Institución papal y los escándalos surgidos en su seno habían recibido las críticas más feroces incluso de los teólogos de la conciliación que empezaban a apoyar que el Concilio debía ser la autoridad superior, incluso por encima del Papa (Suárez Villegas, 2010,174-175). Por su parte, el cambio en el plano económico muestra la gran diferencia entre la economía monetaria de la ciudad, madre incipiente del capitalismo, y la economía campesina ligada a la agricultura y estancada en su crecimiento, que también tiene su reflejo en el alto y bajo Clero.

Todos estos componentes cristalizaron en lo que se conoce como la Reforma protestante que supuso una auténtica revolución eclesiástica en la Europa Occidental dominada durante toda la Edad Media por la Iglesia católica (Gaarder, Hellern y Notaker, 2016, 213-214). A esta Reforma se la conoce como «el movimiento de renovación evangélica surgido en Alemania en la segunda década del siglo XVI y promovido por el monje agustino Martín

${ }_{17}$ San Agustín, entre otras muchas cosas, establecía que la naturaleza del ser humano estaba afectada por el pecado original y que esta perjudicaba tanto a su entendimiento como a su voluntad. Dicho concepto es compartido, en parte, por reformadores como Lutero.

18 Juan Calvino, una de las grandes figuras de las Reformas Protestantes, estaba formado en el Humanismo. 
Lutero (1483-1546)» (Filoramo, Massenzio, Raveri y Scarpi, 2012, 167). Los y las expertas manejan la fecha de 1517 como inicio de esta Reforma, cuando Lutero publicó sus noventa y cinco Tesis en la víspera de Todos los Santos, y la fecha de 1564 como final de este período, con la muerte de Juan Calvino (1509-1564) (Márquez Carrasco, 2010, 256).

Pero a la Reforma protestante se le puede otorgar perfectamente la denominación de «Reformas» ya que no surgió de un único pensamiento sino que diferentes autores con un proyecto común fueron después diferenciándose en cuestiones doctrinales, espirituales, institucionales e incluso de interrelación con la sociedad. Este es un movimiento muy complejo que tiene cuatro características principales: es internacional, multiforme, unitario, en cuanto a su núcleo esencial, y constante (Filoramo, 2001, 452-456). Es internacional porque surgió en varios puntos de Europa y más adelante se expandió por muchas de las regiones colonizadas en ese momento. Hay que señalar que aunque Lutero fue el que tuvo la iniciativa, lo cierto es que en otras zonas de Europa aparecieron simultáneamente rupturas religiosas y filosóficas de este tipo.

Asimismo, es una corriente multiforme ya que «la reforma clásica» (Filoramo, Massenzio, Raveri y Scarpi, 2012, 180-181) ${ }^{19}$ nació pluriforme. «Desde un principio su pluralidad fue congénita y caracterizó su unidad, profunda por una parte y precaria por otra» (Filoramo, 2001, 453). En el inicio, los autores reformistas tuvieron diferentes visiones en cuanto a la doctrina a seguir y todo lo que ello implicaba. Esta situación llevó a la aparición de diversos protestantismos (Márquez Carrasco, 2010, 256; Rivera García, 2010, 210-211; Filoramo, Massenzio, Raveri y Scarpi, 2012, 169-170) ${ }^{20}$ con

19 El Anglicanismo, que se inserta dentro de los Protestantismos, tiene sus propias reglas de nacimiento. Está unido a la figura del rey Enrique VIII (1509-1547). Surge por razones políticas y personales del monarca más que por razones teológicas o ideológicas. La separación de Inglaterra de la doctrina romana no responde a que Enrique VIII fuera un luterano o protestante convencido, sino a su enfrentamiento con el Papa por su divorcio con Catalina de Aragón. De hecho polemizó con las hipótesis de Lutero e incluso persiguió a los evangelistas ingleses durante la década de los años veinte del siglo XVI. La iglesia anglicana establece, tanto por mandato real como parlamentario, que el rey es el «jefe supremo en la tierra», creando una Iglesia nacional. Esta confesión mantenía una gran semejanza con la dogmática y la liturgia católica, pero predicaba la separación con la jerarquía de la Iglesia romana. De todas maneras, fue la puerta de entrada, en este Estado, de numerosas confesiones protestantes. Más adelante esta fe evolucionó compaginando elementos católicos, luteranos y calvinistas. La historia religiosa inglesa es altamente recomendable, sumamente compleja y decisiva para numerosos acontecimientos de la realidad constitucional y parlamentaria inglesa.

${ }^{20}$ Las Reformas Protestantes fueron pluriformes y multiformes. Los diferentes autores de esta doctrina que divergieron en los razonamientos primigenios de Lutero llevaron a la práctica la heterogeneidad de las distintas visiones cristianas de la Reforma que fue- 
una raíz común pero con elementos divergentes. La pluriformidad conllevaba la defensa del principio de la libertad de conciencia desde el ámbito religioso ya que ante los distintos protestantismos era necesario un respeto común. Este elemento multiforme también se evidenció en las concepciones políticas que manejaban los protestantes, ya que este movimiento reformador llevó sus convicciones más allá de la teología, con el fin de establecer una sociedad y un estado diferente basado en su fe. Es verdad que no instituyó una teoría política sistematizada, homogénea e igualitaria entre todos sus miembros y con un razonamiento claro. Tanto es así que los propios autores fueron variando, en ocasiones, sus planteamientos sobre cuestiones básicas en cuanto a la forma de organización del poder.

ron trasladadas a diferentes territorios. Además de Lutero, Calvino (1509-1564) fue el otro gran referente del movimiento. Este autor ginebrino que fue uno de los principales en cuanto a la implantación de la reforma y su posterior difusión, escribió la Biblia de Ginebra en 1560, y tiene una explicación que concuerda en muchos puntos en Lutero, pero también difiere en muchas de las cuestiones primordiales de las argumentaciones del autor alemán. Se le conoce por haber establecido la jerarquía eclesiástica más eficaz dentro de las confesiones protestantes. Sus concepciones se expandieron a otros lugares como Francia, Países Bajos, Escocia y las trece colonias americanas, aunque cada región y sus fieles adaptaron las reflexiones de Calvino a sus propias circunstancias culturales, sociales, territoriales y políticas; lo que muestra la gran heterogeneidad del Protestantismo. Muchos autores lo definen como el político de la Reforma. Desde luego la complejidad teológica y jurídica de Calvino es apabullante y sumamente enriquecedora, y a nivel espiritual tuvo un gran papel, suya es la idea de la voluntad divina y de la predestinación de los hombres. En cuanto a su conceptualización política, defendía la concepción de una sociedad reformadora; es decir, lejos de fundar sociedades aisladas de creyentes sin relación con el resto de los espacios de la convivencia social, Calvino defiende el respeto a las instituciones temporales, a las instituciones políticas, sin sacralizarlas. En esta misma línea, no es un separatista Iglesia/Estado en sentido estricto, ya que entiende que el poder político y las leyes derivadas de él son parte del ámbito terrenal y no tienen una dimensión divina, pero éstas sí deben buscar los objetivos de Dios, que son la justicia y el bien común a través de la equidad y la caridad.

Pero otros pensadores también desarrollaron distintas doctrinas protestantes, como por ejemplo Ulrich Zwinglio (1484-1531), que fue discípulo de Lutero e implantó la Reforma en Suiza. A pesar de compartir muchos análisis con su maestro, también evolucionó en cuanto a su razonamiento y llevó a posiciones más radicales elementos como la prohibición y el repudio de las imágenes. Además, a este autor se le reconoce la creación de una Iglesia más ordenada e independiente del poder político que la luterana.

Los anabaptistas formaron el ala más radical dentro del Protestantismo ya que estaban en contra de la religión de masas. Ellos creían en comunidades cerradas y en fieles que no podían participar en la vida pública y política del Estado. Y además, estaban en contra el bautismo infantil. Alguno de los autores más destacados fueron Guillermo Reublin y Juan Brötli. 
No obstante, este también es un movimiento unitario ya que su núcleo esencial ha sido compartido por todos los credos derivados de esta doctrina religiosa: la palabra de Dios es la única que renueva y la única capaz de alcanzar la salvación a través de la fe en Cristo. Es decir, para esta doctrina religiosa la única autoridad es la Biblia ${ }^{21}$, descartando la tradición. Sólo ella contiene la palabra de Dios y, por tanto, su autoridad es superior a la autoridad de la Iglesia y a la del Papa. Así, las Reformas protestantes pusieron en jaque a la organización institucional eclesiástica. Eliminó a los intermediarios de la palabra de Dios, como los Santos y la Virgen que dejaron de ser objetos de devoción para ser modelos a seguir, y otorgó una función principal a los laicos, esto es, a los creyentes no ordenados, que tenían prohibido la lectura de la Biblia por la Iglesia Católica (Filoramo, Massenzio, Raveri y Scarpi, 2012, 168-169).

Finalmente, es un movimiento constante porque aunque su punto de partida comenzó en 1517, estamos ante una corriente cristiana que ha ido creciendo a lo largo de los siglos y ha ido cambiando según evolucionaba la sociedad. Además, diferentes formas de protestantismo han ido apareciendo desde la Reforma en adelante, en sentido estricto. Igualmente, existen interesantes precedentes como John Wyclif (1320-1384), que ya difundía en el siglo XIV que la voluntad de Dios era accesible a todo el mundo a través de la Biblia (Wyclif, 1382).

Este credo no sólo hablaba de religión, espiritualidad y fe, sino que también tuvo repercusión en la rama filosófica y humanista, tratando tanto la naturaleza del ser humano, las características de la sociedad, la ciencia y el poder en sí mismo (Suárez Villegas, 2010, 165-168). Sin olvidar su trascendencia religiosa y su visión de Dios, piedra angular de su existencia, debemos entender que sus incursiones en otros espacios de pensamiento y práctica afectaron de manera trascendental a la sociedad del siglo XVI que salía de la premodernidad y empezaba a adentrarse en la modernidad. Los postulados que conformaban al individuo durante la Edad Media comenzaron a ser sustituidos por nuevos valores que estarían en la base de los individuos protagonistas de las revoluciones liberarles de los siglos XVII y XVIII.

Uno de los elementos de la filosofía reformadora, en todas sus doctrinas, fue su visión de la palabra de Dios, es decir, el nexo de los fieles con el «Creador» debía ser individual y por tanto directo, sin intermediarios. Para conseguir esa relación directa había que profundizar en la lectura de la Biblia que era donde venía la palabra del Señor. Esta idea, que en realidad volvía al cristianismo primitivo, fue absolutamente revolucionaria en esta época

${ }^{21}$ Para Lutero era fundamental estudiar profundamente el griego y el hebreo como lenguas originales de la Biblia, de hecho sigue siendo parte la formación de los sacerdotes luteranos. 
porque amenazaba a la autoridad eclesiástica católica y a su interpretación de las Sagradas Escrituras. Durante la Edad Media, la población conocía la palabra del «Salvador» a través de las interpretaciones del Clero y de la máxima autoridad de éste. El protestantismo criticó que el catolicismo de esta época estuviera muy alejado de la fe y se hubiera instalado en tradiciones religiosas que nada tenían que ver con la raíz de la creencia cristiana y que eran utilizadas en el propio beneficio de la institución, no de los fieles. Por ello, utilizaron la educación para instruir a la comunidad en el conocimiento directo de las Escrituras. La invención de la imprenta apoyó este modelo. Además, supuso la alfabetización de muchas personas que, al tener mayor conocimiento, participaban de forma más activa en su círculo religioso pero también en el social (Suárez Villegas, 2010, 166-173). La simplificación de los oficios religiosos, haciéndolos más accesibles para la comunidad, también fue uno de los puntos fuertes de esta Reforma.

Unida a todas estas nociones se desarrolló otro argumento. El poder de la Iglesia Católica era tan vasto que se había expandido también hacia el ámbito civil de los Estados o territorios. Así, la no separación Iglesia/Estado era tal que las personas podían comprar «indulgencias» para perdonar sus pecados, incluso si éste coincidía con un delito civil. Ello traía consigo una situación de desigualdad clara, las personas con posibilidades económicas podían acceder a esta clase de justicia mientras que el estamento social más pobre no tenía acceso ni al perdón divino y a su salvación, ni a la condonación civil de sus delitos. La Reforma criticaba la concentración del poder moral, económico y político de esta Institución.

Los reformadores sostenían que todas las actividades profesionales eran igual de importantes para Dios y no había diferencias entre los fieles por razón de su trabajo. Ello suponía que el sacerdocio no estaba por encima del resto de actividades profesionales, era una función más dentro de la Iglesia, pero en ningún caso creaba dos categorías distintas de creyentes. Estaban en contra de la autoridad moral del clero católico. Los hombres sólo eran responsables antes Dios, por tanto el Clero no podía exigirles responsabilidad de ningún tipo, ni espiritual y moral, ni por supuesto civil. Los pensadores protestantes criticaban la jerarquía católica y defendían un valioso papel de la comunidad frente al rol de las autoridades, que suponía poner en entredicho la soberanía del Papa (Márquez Carrasco, 2010, 256).

Como bien dice Juan Carlos Sánchez Villegas, «la Reforma protestante es ante todo una crítica a un catolicismo caduco e institucionalizado que había degenerado en burdas formas de dominación social a través de sus prerrogativas religiosas. La religión convertida en servidumbres que rindiesen los méritos suficientes para ser merecedor de la gracia divina. Esta será la idea contra la que combatirán todos los reformadores, que presentan la fe como una acción de Dios en la persona, un regalo que otorga capacidad de percibir 
la vida con una fuerza renovada que genera un cambio en su naturaleza» (Suárez Villegas, 2010, 167). Este autor defiende una reflexión que resulta muy esclarecedora: la Reforma planteó una «Iglesia invisible» que se sustentaba en la fe de las personas practicantes, frente a la «Iglesia visible» y organizada bajo una fuerte estructura jerárquica que con el devenir de los tiempos se había empapado de los defectos desarrollados por la ambición del poder.

Pero las consecuencias de esta argumentación van más allá. La vida del creyente según los reformadores no era una vida pasiva donde se realizaban obras para buscar la gracia del «Creador», sino que debía seguir un modelo justo, un modelo de vida protestante, y para eso las personas tenían que convertirse en sujetos activos de su propia vida. Y este argumento se trasladaba al espacio social y político, donde también se debía seguir este prototipo reformador. Para conseguirlo era necesario que los seres humanos pudieran desarrollar en libertad su fe, esto es, era indispensable que se respetara su conciencia como individuo. Así, la libertad y el individualismo se convirtieron en elementos inapelables para desarrollar la fe protestante en todos los espacios de la vida (Troeltsch, 1958, 17-18).

Como ya hemos visto, el sacerdocio no existía de la misma manera que en la Iglesia católica. Para el protestantismo era la comunidad de fieles en su conjunto la que tomaba las decisiones sobre la dirección y la gestión de su vida espiritual. Es decir, determinaban conjuntamente sus resoluciones, basadas en la libre asociación de sus miembros. Dicha doctrina es precedente del argumento liberal que fundamenta la organización política de un estado en un pacto entre ciudadanos iguales ${ }^{22}$.

Planeaba también el asunto de que la Iglesia no podía situarse fuera de lo que pasaba en las sociedades -no desde la injerencia católica, donde se había llegado a una corrupción también del poder civil y político-, sino que con las acciones de todos y cada uno de los miembros de la institución eclesiástica había que reformar la sociedad. Y aunque no estamos ante la separación estricta Iglesia/Estado tal y como la conocemos actualmente, sí se muestra una concepción profunda y distinta de cómo la religión debe afectar y estar presente en todos los ámbitos de un país. Pero muchos reformadores abogaban por la disociación entre la comunidad política y la comunidad religiosa, en cuanto a sus funciones. Según Juan Carlos Suárez Villegas, los cristianos tenían como objetivo vital «convertir su fe en el motor activo frente a una sociedad que le impida vivir con valores cristianos», y dicha forma compleja de entender la correlación del individuo con la Iglesia, «como una asociación

${ }^{22}$ Esta teoría liberal que cambió la forma de organización política del mundo moderno pero que también tuvo grandes contradicciones ya que en la práctica ese pacto entre ciudadanos iguales no era universal. En el concepto de ciudadanía no se incluían ni a las mujeres, una gran parte de la sociedad, ni a los esclavos. 
voluntaria de creyentes», afectaba también al concepto de «participación política y, por ende, a la noción de ciudadano» (Suárez Villegas, 2010, 180).

Desde este punto de vista, Calvino hizo una reflexión sobre la separación del poder temporal y el poder espiritual desde las raíces de la libre conciencia. Para este autor la dimensión interior del pensamiento del individuo dependía de la trascendencia, de Dios, y por esa razón quedaba excluido de la injerencia de las leyes políticas exteriores y no divinas, defendiendo la conceptualización de los derechos subjetivos (Troeltsch, 1958, 22-ss.). Además, el siguiente paso en la deducción de Calvino fue que esa defensa de la libertad de conciencia evolucionara hacia la protección de la libertad de cultos, sobre todo porque durante muchos años estaba prohibido profesar el credo reformador de Calvino. Hubo que esperar hasta 1648 para que fuera permitida (Suárez Villegas, 2010, 215-220). Esta defensa de la libertad de cultos se basaba fuertemente en la noción de tolerancia como posibilidad de elegir la fe. Frente al monopolio cristiano de la Iglesia católica se abogaba por abrir el abanico a la hora de elegir otros cultos. Ahora bien, no entraba en la tolerancia ni en la libre elección de que los individuos pudieran optar por ser ateos o laicos, que no tuvieran una religión (Peces-Barba Martínez, 1989, 61). Es por eso que todavía no estamos ante una plena libertad de conciencia y religiosa, tal como se entiende hoy en día. La concepción de tolerancia es mucho más adecuada para este momento histórico y social. Todo ello nos lleva hacia el argumento de que los protestantes utilizaron su dogma como un núcleo intocable por el poder político, convirtiendo su identidad religiosa en un límite a dicho poder estatal. En este mismo sentido, y en lógica con la lucha y con los acontecimientos que rodearon a esta Reforma, la libertad para decidir sobre la fe del ser humano debía ser también inquebrantable.

Finalmente, los pensadores de este movimiento como Calvino o Lutero también razonaron sobre la resistencia al abuso y al exceso del poder del rey. Ellos eran defensores del ius resistendi ${ }^{23}$, no del tiranicidio. Estos autores propugnaban que el pueblo debía reflexionar sobre cómo habían acabado en esa situación. Este ius resistendi se configuraba como un derecho que poseía la sociedad para enfrentarse legítimamente al poder político temporal, encarnado en una autoridad -el rey-, cuando hubiera llevado a cabo conductas que se consideraran ilegítimas (Carvajal, 2000, 343-346; Hancock, 1989, 27;

${ }^{23}$ Este ius resistendi no nace con el protestantismo, sino que existe anteriormente en la filosofía política de Occidente. Ya autores medievales como Guillermo de Ockham y Marsilio de Padua tuvieron una importante contribución en este concepto. Además, este derecho a la resistencia se configura como uno de los fundamentos reconocidos en las declaraciones de derechos de los estados liberales. Así se produjo en la Revolución francesa, que se constitucionaliza como un derecho natural e inalienable, en la Declaración de Derechos del Hombre y del Ciudadano. 
Carvajal, 1992, 78-79). Pero sobre todo, ambos defendían que otros poderes intermedios, antes de llegar al monarca o al emperador, tenían la responsabilidad de acabar con dicha realidad. Esta cuestión se puso en práctica en el Imperio germano, donde los príncipes alemanes fueron instados, y así lo hicieron, a luchar contra el Emperador Carlos V para defender la libertad de elección de la fe por parte de la ciudadanía (Edelmayer, 2001, 152-153).

Una de las claves de estas Reformas no fue el protestantismo en sí, por lo menos desde la óptica de la organización del poder, sino la ruptura con la Iglesia católica. Ello acarreó consecuencias en el panorama político europeo que se entremezcló con el conflicto religioso. Lutero, tras la publicación de sus noventa y cinco Tesis, fue perseguido por la Iglesia católica y la bula papal Exsurge Domine, publicada el 15 de junio de 1520 por el Papa León X, buscaba la retractación en cuanto a sus hipótesis. La quema de dicha bula por parte del protagonista de la misma supuso su excomulgación el 3 de enero de $1521^{24}$. La protección del príncipe de Sajonia, Federico el Sabio, consiguió evitar su condena.

A partir de este momento el luteranismo comienza a divulgarse por el Imperio. Por un lado, muchos príncipes vieron con buenos ojos este carácter rupturista del nuevo cristianismo, pero dicho espíritu también fue acogido por los sectores más descontentos de la sociedad. La baja nobleza y el campesinado germano basaron sus acciones en estas nuevas hipótesis para iniciar revueltas contra príncipes y contra el Emperador que tuvieron un fin muy sangriento ${ }^{25}$. Lutero fue contrario a estos movimientos del pueblo y giró su mirada hacia los príncipes alemanes en el razonamiento de que la Iglesia y el Estado no iban separados y la primera tenía la responsabilidad de activar el sentido cristiano en la vida social y política de una ciudad (Filoramo, Massenzio, Raveri, Scarpi, 2012, 170), y de un reino. En 1535 cincuenta y una ciudades libres alemanas habían implantado la Reforma. La visión del hombre como un ser legítimo con las cualidades necesarias para desarrollar sus creencias, más allá de lo que dijera una organización institucional religiosa, dio también poder al individuo como ser político para participar en la sociedad por razón de su fe (Suárez Villegas, 2010, 166). Esta idea fue utilizada por los príncipes para reivindicar el poder político frente al Emperador.

Como la Reforma no sólo surgió con Lutero, otros pensadores europeos, impulsados por su arranque, emprendieron también una lucha de implantación política de los distintos movimientos protestantes. Es el caso de Estrasburgo con Martín Bocero, Zúrich con Zuinglio, o Ginebra con Juan Calvino. Otros lugares donde la Reforma se propagó y se implantó con distinto ritmo fueron Suecia, Noruega o Escocia. Desde luego cada ciudad, reino y región

\footnotetext{
${ }^{24}$ Bula papal Decet Romanun Pontificem.

${ }^{25}$ «La revuelta de los caballeros», de 1522, y la «guerra campesina» de 1524 a 1525.
} 
tuvo su propio contexto y sus propios elementos que marcaron las diferencias entre unos y otros, y por tanto no hubo una uniformidad estricta en la expansión de este movimiento ni en la relación que nació después de su implantación con la Iglesia católica.

Todo este apoyo a las Iglesias de la Reforma trajo consigo el divorcio con la organización católica. Aun así, los príncipes alemanes buscaron una conciliación religiosa con el fin de mantener la paz entre las diferentes regiones del Imperio. Se celebraron coloquios y dietas que tenían como objetivo resolver las diferencias entre las distintas confesiones reformadoras, así como acercar el protestantismo y el catolicismo en una convivencia pacífica. Pero la confrontación llegó con las guerras religiosas que afectaron al Imperio en la lucha entre Carlos V y los príncipes germanos, pero que también tuvieron consecuencias en otros lugares del continente europeo. La paz de Ausburgo de 1555 puso sobre el tapete la división confesional de Europa, y se reconocieron la católica y la luterana. En esta paz se estableció el principio cuius regio eius religio, el que gobierna una región o un territorio determina cuál es su religión. No se reconocía la libre actuación religiosa de los individuos, sólo se reconocía la del príncipe. Así, sus súbditos debían profesar la misma confesión que quien los gobernara. No obstante, también se instauraba el derecho de aquellas personas que no profesaran la religión del príncipe a emigrar. Estamos aquí ante un concepto primitivo de tolerancia, que fue un primer paso importante para poder seguir el camino hacia la futura libertad religiosa.

Sin embargo Europa, aunque había dado pasos, seguía sin reconocer numerosas doctrinas protestantes que tenían su implantación entre la sociedad de algunas ciudades y que no podían ser ignoradas debido a su relevancia religiosa y política. Habrá que esperar hasta el final de la confrontación de los Treinta años (1618-1648), con la firma de la Paz de Westfalia, para que se produjera el reconocimiento de la Iglesia calvinista. La historia nos muestra que en esta lucha por el reconocimiento confesional no siempre las dos grandes Iglesias protestantes actuaron conforme a lo que predicaban para ellas. Durante el siglo XVI fueron apareciendo diferentes grupos que entendían la Reforma y el cristianismo desde una visión distinta a la católica, a la protestante y a la calvinista. Estas comunidades fueron perseguidas incansablemente por las tres Iglesias establecidas. Es el caso de los baptistas o los socinianos, entre otros (Kamen, 1987, 22-72). Sucede entonces con estas doctrinas lo mismo que sucedió con la fe católica y con la luterana en sus orígenes: cuando eran proscritas por el poder establecido (el Imperio Romano, el Sacro Imperio Romano Germánico o la propia Iglesia Católica) defendían fehacientemente la tolerancia y la libre elección de culto. Pero cuando se aunaron con el poder, en el Imperio romano o con los príncipes alemanes, persiguieron a todos aquellos que no pensaran y actuaran como ellos, ya que 
en el núcleo de esta actuación se encontraba el pensamiento de ser las únicas Iglesias verdaderas.

Mientras, comenzó un movimiento dentro de la organización católica que buscaba frenar el avance de estas nuevas confesiones. A dicho movimiento se le conoce como la Contrarreforma. La irrupción del protestantismo, en sentido amplio, supuso un cisma religioso para la Europa católica que dividió no sólo a la cristiandad sino también a las sociedades. Fue con la celebración del Concilio Ecuménico de Trento, en 1545, que se quiso iniciar el camino reformador de la Institución apostólica y romana. Varias cuestiones fueron tratadas. Entre ellas, la reestructuración de la organización eclesiástica, la transformación de las órdenes religiosas volviendo a la tradición, y la renovación moral e intelectual del Clero con el fin de acabar con la corrupción que había asolado a esta Iglesia durante gran parte de la Edad Media. Este Concilio también ratificó la supremacía papal frente a otros órganos como la asamblea de los obispos (Pesch, 2002, 267-281) . En este Concilio se trató, en numerosas de sus sesiones, la cuestión del protestantismo y la posibilidad de mantener un diálogo con sus defensores, hecho que finalmente no llegó a materializarse. Uno de los protagonistas políticos destacados en este Concilio, fue Carlos I de España y V de Alemania (Letocha, 2005, 3-34).

Fue la Paz de Westfalia, y sus Tratados, los que trajeron consigo la igualdad de la confesión católica, luterana y calvinista, además del nacimiento de un nuevo tipo de relaciones internacionales entre los estados y del desarrollo del primer modelo capitalista. Además se estableció la posibilidad de que aquellas personas no pertenecientes a ninguna de estas tres organizaciones religiosas pudieran, de manera privada, realizar los actos de aquella fe que dictara su conciencia. Así, los Tratados reconocían el principio de tolerancia, en este caso de cultos. Marcó el inicio hacia la futura pluralidad religiosa confesional en el viejo continente y en otros territorios. Porque la Guerra de los Treinta años, que se produjo por diferentes motivos territoriales, de poder y económicos, también tuvo un fuerte componente religioso y cultural. La división europea entre protestantes y católicos fue una de las causas principales de este conflicto bélico (Márquez Carrasco, 2010, 260-262) ${ }^{26}$.

${ }^{26}$ Dicha contienda comenzó en el Imperio Romano Germánico, gobernado por la Dinastía de los Hausburgo, fuertemente católica, que quería, entre otras razones geopolíticas, dominar el territorio a nivel religioso. Pero fueron interviniendo distintos países que eligieron bando dependiendo de si apoyaban al Protestantismo o al Catolicismo. Con respecto a la primera confesión religiosa, apoyaron a los príncipes alemanes países como Dinamarca, Suecia, Provincias Unidas (Holanda en su gran mayoría) e Inglaterra. Del lado católico se situó el Imperio español. Francia se unió a la liga protestante, a pesar de ser católica, porque sus motivos principales para entrar en la contienda no versaban sobre religión. 
Esta Paz aseguraba el respeto de cultos religiosos en todo el Imperio proclamando por escrito la tolerancia religiosa, la libertad de conciencia y la libertad de culto. Unido a ello, se puede dilucidar que se produce un debilitamiento del Imperio ${ }^{27}$, porque como proyecto político empezaba a tambalearse dando paso a estados hegemónicos, basados en el concepto de soberanía de Hobbes (Hobbes, 2014, 153-178) o Bodino (Bodino, 1997, 54-65). Asimismo, su nueva posición arrastró a la Iglesia católica que veía como sus aliados más significativos, el Imperio Germano y el Imperio español, perdían posiciones dentro del tablero político y económico europeo. Y así, la Contrarreforma también se vio afectada negativamente por esta Paz de Westfalia. Igualmente, el centro neurálgico del continente se trasladó hacia el norte, hacia la actual Holanda y la Inglaterra de corte protestante, centro que antes estaba más ubicado en las regiones católicas (Márquez Carrasco, 2010, 264-266). Es por todo ello que lo que se origina con estos Tratados de Paz es conocido como «paradigma Westfaliano», es decir, el nacimiento de los Estados nacionales soberanos (Toscano Franca Filho, 2006, 100-104).

\section{IV.EL SINUOSO CAMINO DE LA FORMALIZACIÓN DE LOS DERECHOS EN ESTADOS UNIDOS Y SU RELACIÓN CON LAS REFORMAS PROTESTANTES}

Desde la segunda mitad del siglo XVII y durante toda la siguiente etapa, los diversos cambios que habían comenzado un siglo antes continuarán su andadura hasta cristalizar en las revoluciones liberales. El razonamiento ilustrado que inundará este momento con su fundamentación en la razón y la ciencia, la separación y el equilibrio de poderes y el concepto de ley como la voluntad general del pueblo ${ }^{28}$ estarán en la base del futuro estado liberal

${ }^{27} \mathrm{La}$ Paz de Westfalia también supuso la autonomía de los príncipes alemanes dentro del Imperio. Podían elegir su religión pero también tenían capacidad para negociar y crear acuerdos con otros Estados, siempre y cuando no fueran en contra del propio Imperio. Esta situación de autonomía y competencia propia siendo parte de un Imperio es el antecedente del federalismo que se instaura más adelante en el Estado alemán.

${ }^{28}$ La ilustración se basa en la razón, es decir, para desterrar el oscurantismo, el despotismo y el absolutismo de otras épocas debemos utilizar la razón y debe ser la máxima para poder entender el mundo donde vivimos. Y ello supone que si utilizamos nuestra razón podremos ser por fin libres y a la vez ser responsables de nuestras actuaciones. Lo que nos diferencia de otros seres vivos justamente es esa razón. Así que se dan dos procesos: uno de racionalización y otro de emancipación, las personas dejan de ser menores de edad dirigidos por un monarca absoluto. Y como consecuencia de esto último, las sociedades en su conjunto comienzan a funcionar basándose en principios racionales y aceptados de manera universal. Dejan de regirse por la autoridad despótica o por las verdades divinas. 
(Barrero Ortega, 2000, 94) y en el nacimiento, por primera vez, de auténticos derechos individuales, subjetivos y de fundamentación universalista. La idea de tolerancia (Locke, 1999) formará parte de la estructura dogmática de la libertad religiosa que se configurará en estos siglos y que será una de las importantes puertas de entrada de los demás derechos y de su sistematización en declaraciones (Böckenförde, 1994, 44-63; Peces-Barba Martínez, 1993, 405; Barrero Ortega, 2000, 95) ${ }^{29}$. Asimismo, el afianzamiento del ius resistendi y su nexo con la libertad ideológica formará parte de los postulados liberales (Carvajal, 1992, 88-94).

Es ahora también el momento en el que el individualismo que ya se venía anunciando desde el ámbito reformador, entendiendo la relación de Dios directamente con el ser humano y la importancia de cómo viven su creencia religiosa, toma una dimensión más amplia y supera el nivel de la fe para saltar a los espacios políticos. La relación con el estado se produce directamente entre el individuo y este, sin que pase por la sociedad entendida como una comunidad sin identificación personal de sus miembros.

Este nexo se plantea a través del pacto entre el ser humano y el poder, donde las personas deciden dotarse de un régimen político de manera libre. Son ellas las que establecen cómo se organizarán políticamente y quiénes representarán a los tres poderes del Estado. Desaparece la concepción del poder divino y se implanta la concepción de que son los hombres y también las mujeres -aunque no todos los autores están de acuerdo con la libertad y la racionalidad de ellas- las que deciden sobre su propio presente y futuro. Se conocen como las teorías contractualistas. Asimismo, estos pensadores confirman la existencia de los derechos y libertades de las personas, que son inherentes a ellas y que no pueden ser arrebatados o eliminados ni siquiera por el poder estatal.

Otro de los hechos destacables fue la secularización que se produce en estos siglos. Ya observamos que en la etapa medieval, prácticamente todos los espacios de la vida estaban inundados por los valores y principios religiosos y por el poder que la Iglesia ejercía en la política y el Derecho. La llegada de los reformadores y la irrupción de la racionalidad, y del valor del método experimental y científico, provocaron el alejamiento de la costumbre y la superstición anterior. Pero esta reflexión sobre la secularización afectó en gran medida al poder político y a la correlación entre la Iglesia y el Estado (Berger, 1983, 123-ss.).

${ }^{29}$ Varios autores establecen que el nacimiento de la libertad religiosa no surge de un puro y único pensamiento racional, sino que surge de los acontecimientos históricos que se sucedieron con y tras las Reformas Protestantes. Será después de estos acontecimientos cuando se dote a la libertad religiosa de una argumentación racional. 
La noción de tolerancia tiene entre el siglo XVI y el siglo XVII un momento de debate crucial compuesto tanto por fundamentos teóricos como por fundamentos históricos que se dieron en esa fase. La semilla de la tolerancia fue uno de los gérmenes que desembocó en el liberalismo que se extendió por el mundo contemporáneo entre los siglos XVIII y XIX (Russel, 2010, 150-ss.) ya que, entre otras cosas, se configuró como un símbolo frente a las intromisiones del poder político en la actuación del individuo. Uno de los hechos que tuvieron consecuencias directas con respecto a la concepción de la tolerancia fueron las luchas de religión (Barrero Ortega, 2000, 102-103) ${ }^{30}$. Éstas se alargaron hasta la Paz de Westfalia y produjeron un gran hastío para la sociedad y los gobernantes del momento. Por tanto, la búsqueda de la tolerancia y de la transigencia en aquellos territorios donde los conflictos religiosos se vivieron durante décadas, fue un gran aliado para buscar el restablecimiento de aspectos cotidianos propios de una vida estatal más o menos ordenada.

Los pensadores ilustrados fueron más allá del concepto de tolerancia reclamado durante los siglos anteriores (Voltaire, 2013, 48-50). Ya no creían en una tolerancia que sólo buscaba la no persecución de las religiones cristianas o la simple aceptación de las mismas. Es ahora cuando se empiezan a deslizar hacia la configuración de la libertad de conciencia y religiosa (Locke, 1999). Gregorio Peces-Barba establece cinco elementos para entender, en este primer momento histórico, cuál es el contenido que se puede desprender de estos derechos. Primeramente, era un derecho de autonomía en el que nadie podía interferir en la conciencia del individuo que la practicaba. En segundo término, sólo se protegía la conciencia religiosa, no había cabida para los ateos o los laicos. En tercer lugar, este derecho actuaba frente al poder político, pero también iba a actuar frente a las tres grandes Iglesias establecidas oficialmente desde la Paz de Westfalia -y la anglicana dentro de la Calvinista-. En cuarto y quinto término, aunque seguía prevaleciendo el derecho individual a la libertad religiosa, se reconoció de manera limitada la libertad de culto, aunque dependía de cada Estado (Peces-Barba Martínez, 1989, 62).

La puesta en práctica de la libertad de conciencia y la libertad religiosa sólo pudo llevarse a cabo con el planteamiento de la separación Iglesia/ Estado. La Reforma otorgó autonomía al creyente frente al poder político, pero eso no significó la defensa por parte de los luteranos, calvinistas y resto de protestantes de esta separación. Aunque dependiendo de qué comunidad o confesión, podía haber una intención más o menos alejada de sus actuaciones

${ }^{30}$ Así, en 1578 Guillermo d'Orange intentó crear un acuerdo con España para reconocer equitativamente a las confesiones católica y protestante, y aunque no tuvo éxito y la división religiosa en las Provincias Unidas continuó a través de enfrentamientos bélicos, es un ejemplo de la búsqueda de tolerancia religiosa. 
religiosas y de sus organizaciones eclesiásticas con respecto al poder estatal, pero no se abogó por una separación rigurosa ${ }^{31}$. Habrá que esperar a la llegada de la filosofía ilustrada para que aquellos componentes reformadores que podían conjugarse perfectamente con la separación entre el poder temporal y el poder espiritual tuvieran éxito.

No obstante, no fue un camino sencillo ya que las tres Iglesias reconocidas no estaban de acuerdo con ello. De un lado, la Iglesia católica no reconoció ni aceptó la concepción ilustrada y se enrocó en el tradicionalismo, rechazando la libertad religiosa y la aconfesionalidad del Estado ${ }^{32}$. Pero las Iglesias protestantes tampoco querían perder su rol en el poder político de aquellos estados que habían acogido que el Jefe del mismo fuera también la cabeza de la Iglesia ${ }^{33}$. Ello trajo consigo que la libertad de conciencia y religiosa que comenzó a plantear la Ilustración y que se expandió con el liberalismo, no fuera aceptada en un primer momento por las mencionadas Instituciones eclesiásticas. A pesar de ello, se implantó en la filosofía de estos siglos que sólo una separación de este calibre podía conseguir que se ejerciera la libertad de conciencia y la libertad religiosa (Souto Paz y Souto Galván, 2010, 23-24; Peces-Barba Martínez, 1989, 62-64).

La doctrina que había detrás de la libertad de creencias tuvo una especial relevancia en las trece colonias americanas de Inglaterra. La Ilustración y sus postulados y la influencia protestante en los derechos y libertades no se produjo en exclusiva en Estados Unidos. Gran Bretaña o Francia son países que tuvieron también revoluciones liberales y en los que podemos encontrar muchos de los elementos que se dieron en este Estado. No obstante, he decidido centrarme en este momento en Estados Unidos para mostrar un ejemplo de país en el que se puede apreciar la influencia de las Revoluciones protestantes en la configuración de la libertad religiosa y del resto de libertades y derechos, en mayor o menor medida. Desde luego, no es el único modelo, pero sirve para plasmar algunas de las cuestiones que han sido expuestas en los apartados anteriores. De ahí su desarrollo en estas líneas.

Desde finales del siglo XVII y durante todo el siguiente siglo, numerosos sucesos acontecieron en América del Norte. Entre ellos, el incremento exponencial de su población, que se debía al crecimiento vegetativo de la misma

${ }^{31}$ De hecho Lutero no era partidaria de ella.

${ }^{32}$ Habrá que esperar hasta la celebración del Concilio Vaticano II en 1965 para que la Iglesia Católica reconociera la libertad religiosa y la aconfesionalidad estatal.

${ }^{33}$ De hecho la aconfesionalidad en muchos Estados protestantes ha sido muy complicada o todavía no se ha producido. Aunque también es cierto que dicha vinculación Iglesia/Estado se ha compaginado con el respeto de otros cultos y actualmente no hay, en principio, Estado democrático que no reconozca el derecho a la libertad religiosa, independientemente de su Iglesia nacional. 
y al gran flujo de inmigración que se produjo a partir de este momento. Más de medio millón de presos británicos ${ }^{34} \mathrm{y}$ de ingleses e irlandeses con poca capacidad económica acudieron a estos nuevos territorios a trabajar como sirvientes en régimen de esclavitud durante cuatro años. Con respecto a la inmigración que se encontraba en condiciones de libertad, empezaron a llegar no sólo ingleses sino también europeos de otros países que, en muchos casos, eran perseguidos en sus regiones de origen por sus creencias religiosas. Más de cien mil alemanes luteranos, más de doscientos mil escoceses presbiterianos, pero también suizos, judíos y hugonotes franceses (Bosch, 2011, 2-4). Las ideas de los pensadores europeos como John Locke o Roger Williams también llegaron al Nuevo Mundo para formar parte de la filosofía y de la gestión política de esta región (Celador Aragón, 2001, 49). La influencia política y filosófica inglesa también fue crucial en las colonias americanas. El documento Petititon of Rights de 1628, y su reconocimiento de derechos, o el Bill of Rights de 1688, que recoge los postulados que se consiguieron tras la Revolución Gloriosa, fueron inherentes a las teorías liberales que se desarrollaron en este territorio (Baylin, 1972, 60-ss.; Holmes, 1986).

Se produjo aquí una apertura religiosa trascendental. Pero la historia de estas colonias no es lineal, en este sentido. Los primeros colonos profesaban en su mayoría la doctrina protestante conocida como puritanismo, nacida de las argumentaciones de Calvino (Vázquez Gómez, 2009, 147-182). Ya desde el inicio de estas colonias la filosofía reformadora se respiraba entre sus habitantes y su gobierno, donde los creyentes eran sujetos activos de la vida política y social de la comunidad y debían actuar conforme a su fe. En Connecticut, en 1638 se aprobaron las Órdenes Fundamentales que reflejaban estas cuestiones ${ }^{35}$. En este aspecto, la Iglesia puritana que se asentó en

${ }^{34}$ Que durante todo el siglo XVIII se sustituyeron por esclavos traídos de África.

${ }^{35}$ Fragmento de las Órdenes Fundamentales de Connecticut de 1638: «Puesto que le ha agradado al Dios todopoderoso, por la sabia disposición de su divina providencia, ordenar y disponer de las cosas en forma tal que nosotros, los habitantes y residentes de Windsor, Harteford y Wethersfield, estamos ahora residiendo y morando a la orilla del rio de Conectecotte y en las tierras alli colindantes; y sabiéndose bien que donde la gente se reúne la palabra de Dios exige que, para mantener la paz y la unión de dicha gente, debiera haber un gobierno disciplinado y apropiado, establecido conforme a [la palabra de] Dios, para que organice y disponga los asuntos de la gente en todas las situaciones tal como la ocasión requiera; por eso, nosotros mismos nos asociamos y unimos para ser como un estado público o comunidad, y en nuestro propio nombre y en el de nuestros sucesores, y en el de todos aquellos que se unan a nosotros en cualquier momento de ahora en adelante, ingresamos juntos en una alianza y confederación para mantener y preservar la libertad y la pureza del evangelio de nuestro Señor Jesús que ahora profesamos, así como también la disciplina de las Iglesias que, conforme a la verdad de dicho evangelio, se practica ahora entre nosotros, asi como también para ser guiados y gober- 
esta zona del mundo rechazó la presencia en el mismo lugar de otras congregaciones o doctrinas religiosas (Souto Paz y Souto Galván, 2010, 25), de tal manera que la discrepancia con la Iglesia oficial podía significar el exilio o un delito castigado con la privación de libertad (Celador Aragón, 2001, 51).

La Institución ortodoxa anglicana, instalada en las colonias, también practicaba esta intolerancia. Por otro lado, también en estos años del siglo XVII se incorporaron textos normativos que reunían contradicciones en materia de religión. Por ejemplo, las Normas Fundamentales de Carolina de 1669 establecían la Iglesia de Inglaterra como única y verdadera religión nacional $^{36}$, para en los siguientes preceptos proclamar la libertad individual de conciencia y el derecho a crear Iglesias (Peces-Barba Martínez, 1989, 60). En Maryland, fundada por católicos, se aprobó en su Asamblea el Acta de Tolerancia que estableció el libre ejercicio de la libertad religiosa y el reconocimiento de la libertad de conciencia religiosa, aunque este derecho no se aplicaba a las personas ateas que podían ser perseguidas por ello. La persecución de ateos también se recogía en Massachusetts, a través de su Cuerpo de Libertades de la Bahía de Massachusetts (Vázquez Gómez, 2009, 154-160), o en Carolina. Por su parte, en Pennsylvania, fundada por cuáqueros, o en Rhode Island (Williams, 2004, 80-131) ${ }^{37}$ se recogían las disposiciones más liberales y tolerantes en esta materia, ya que se reconoció que las personas debían ser respetadas en cuanto a su opinión religiosa, pudiendo disfrutar con libertad de sus pensamientos y juicios (Jellinek, 2000, 93-95). Así, en Rohde Island se reconoció la libertad religiosa para cristianos, judíos, turcos y paganos. Una cuestión esencial aquí fue que todos los habitantes debían obedecer las leyes dictadas sólo en cuestiones civiles; de este modo, la religión no debía ser parte de la legislación aprobada (Asimov, 2012, 139-141; James, 1999, 33-ss.).

La llegada de muchos inmigrantes a las trece colonias pertenecientes a otros grupos religiosos fue desbordando paulatinamente las férreas posturas de prohibición de libertad que se vivían en algunos emplazamientos y

nados en nuestros asuntos civiles según las leyes, reglas, órdenes y decretos que se hagan, ordenen y decreten como sigue».

${ }^{36}$ La Iglesia de Inglaterra se asentó mayoritariamente como la Iglesia oficial en las colonias del Sur.

${ }^{37}$ Rhode Island fue creada por Roger Williams (aunque ya se conocía anteriormente, pero no se denominaba de esta manera), un importante teólogo que defendió la tolerancia y la separación Iglesia/Estado y defensor de los nativos americanos. Su llegada a este territorio se produjo tras su expulsión de Massachussets por sus creencias religiosas. Sus ideas religiosas en materia de libertad y sus profundas creencias democráticas se pueden apreciar en la creación de Providence como zona de libertad de culto. Permitió la libertad religiosa desde su inicio. Él era baptista y se le atribuye su implicación en la creación de las primeras Iglesias baptistas en Estados Unidos (1636). 
ayudaron a afianzar la tolerancia y la libertad de creencias en aquellos otros donde ya desde finales del siglo XVII se recogían en sus documentos jurídicos de convivencia. Además, surge en pleno siglo XVIII el primer Gran Despertar (Great Awakening) que no era otra cosa que la explosión de religiones por todo el territorio. Numerosos evangelistas que no pertenecían a las Iglesias dominantes y oficiales recorrían las regiones proclamando sus ideas y buscando fieles que se adhirieran a sus reflexiones y a su forma de ver la vida. Ello supuso la aparición de numerosas congregaciones que rompieron definitivamente con el concepto de una estructura eclesiástica única, dominante o nacional. Además, muchos de los adeptos que ganaron estos predicadores eran personas pobres que acudían seducidas por el discurso contra la autoridad y contra la acumulación de los bienes. Se hicieron eco de demandas de carácter social que afectaban a la situación económica de los más desfavorecidos, exceptuando a los y a las esclavas (Bosch, 2011, 4; Celador Aragón, 2001, 51).

Por otro lado, existía diferenciación social y económica. Aunque algunos autores mantengan que había igualdad entre los norteamericanos (García Portela, 2014, 53), lo cierto es que la diferencia económica era muy importante y así se demostró en las distintas revueltas rurales que se produjeron desde 1740 (Bosch, 2011,3). Lo que resulta más ajustado a la realidad es que en esta zona del mundo se conjugaron diversos factores que propiciaron el germen de los principios ilustrados y liberales que estaban en el centro de la ideología revolucionaria que impulsó la independencia de los Estados Unidos de América. Uno de los aspectos que ayudó a todo este proceso fue la influencia del protestantismo en la política y en el ámbito social (García Trujillo, 1997, 474). Sus argumentos contra el poder absoluto, el apoyo a las teorías pactistas, su conocimiento de las hipótesis ilustradas y la libertad de conciencia fueron sustanciales (Tocqueville, 1978, 57) ${ }^{38}$. Por ejemplo, el concepto de libertad de conciencia y de libertad religiosa se convirtió en parte de la ideología política revolucionaria de la región (Souto Paz y Souto Galván, 2010, 25-26).

Tanto es así que el hecho religioso tuvo una gran influencia en la Guerra de Independencia de los Estados Unidos de América. Las colonias que profesaban la oficialidad de la Iglesia anglicana defendieron a la metrópoli. Sin embargo, aquéllas que apoyaban otras confesiones religiosas se unieron para conseguir independizarse del sometimiento inglés. Estos territorios dejaron atrás sus diferencias religiosas para unirse en una causa común, y ello favoreció la ampliación del concepto de libertad religiosa. Antes se entendía como una libertad que se aplicaba de manera exclusiva al grupo religioso que

38 Tocqueville mantenía que «el puritanismo no era solamente una doctrina religiosa; se confundía en varios puntos con las teorías democráticas y republicanas más absolutas». 
la proponía, sin embargo en este momento se empieza a configurar como un derecho que puede ser ejercido por todas las personas que conforman esa sociedad (Celador Aragón, 2001, 39). Pero la evolución de la tolerancia y la libertad religiosa fue zigzagueante y evolucionó a lo largo de los años de la lucha armada. Al inicio del enfrentamiento de Independencia, algunas colonias comenzaron a proponer cambios legislativos que tenían como objetivo derrocar a las Iglesias oficiales en dichas regiones, pero con el paso de los años y la intensificación de la batalla, la libertad religiosa se conformó como una de las reivindicaciones expresadas frente al gobierno inglés (Mora Mérida, 1992, 39).

Asimismo, es en plena batalla cuando las colonias, basándose en el autogobierno por el que estaban luchando, comenzaron a redactar auténticas declaraciones de derechos donde se introdujo la protección de los mismos, así como las tesis liberales que avanzaban por las tierras americanas. La aprobación de estas declaraciones comenzó en 1776 pero se alargó en el tiempo más allá de la finalización de la contienda bélica. La influencia de los documentos jurídicos ingleses del siglo XVII -como el Petition of Rights o el Bill of Rights (Baylin, 1972, 60-ss; Holmes, 1986)- en la redacción de estas declaraciones fue palmaria. Las declaraciones norteamericanas recogían la libertad religiosa como el primer derecho a proteger y lo situaban en la posición en la que se configuraba en ese momento: un derecho que abría las puertas a otros derechos naturales, individuales, inalienables y exigibles al Estado (Aparisi Miralles, 1990, 214-216). La manera de regular este derecho no fue homogénea en toda la región y dependiendo de lo previsto en cada uno de los Estados de EEUU se puede distinguir la amplitud de la libertad religiosa y también la existencia o no de la separación Iglesia/Estado.

En numerosas ocasiones, la configuración más extensa de una libertad religiosa iba acompañada de una separación más estricta entre el poder político y el poder religioso. Esta diferencia es mucho más profunda de lo que parece ya que queda anclada a la propia visión ideológica y filosófica de los redactores de los Bill of Rights y de las constituciones estatales. Cuando las colonias circunscribían su libertad religiosa meramente a las personas que creían en una fe, estaba detrás la doctrina del inglés John Locke (Locke, $1999,90)$ que entendía que dicha libertad no debía reconocerse ni para las personas católicas ni para las personas ateas. En cuanto a la separación entre la esfera política y la religiosa, este autor proponía una distinción clara (Celador Aragón, 2001, 68). Por su parte, Jefferson (Jefferson, 2014, 100-ss.) y Madison (Madison, 2005, 83-ss.) siempre mantuvieron el carácter universal de esta libertad, explicando de manera expresa que los no creyentes y las personas ateas debían estar incluidas en el alcance y en el contenido de este derecho. Por supuesto defendían una tajante separación entre la Iglesia y el 
Estado (Celador Aragón, 1998, 29-33). Sus principios se reflejaron en las regiones más progresistas en cuanto a este punto.

Aunque cada declaración de derechos o constitución de los Estados tiene su propia redacción sobre esta materia se pueden agrupar, en su gran mayoría, en dos grandes grupos. Primeramente, nos encontramos con aquellas circunscripciones estatales que poseían una configuración más conservadora sobre la libertad religiosa y la libertad de conciencia. Aquí, se recogía esta libertad únicamente para los fieles. Ello supuso que no se constituyó un derecho de manera universal; así, esta redacción se acercaba a la discriminación por razón de religión e incluso de opinión e ideología. Además, no se establecía una verdadera separación Iglesia /Estado ya que en sus articulados se preveía la creación de un impuesto para las confesiones religiosas ${ }^{39}$. En el caso de Massachusetts se estableció la confesionalidad cristiana de este Estado. El artículo II de su Constitución (1780) dice que «Todos los hombres en sociedad tienen el derecho, así como la obligación, de rendir culto públicamente y en las fiestas establecidas al Ser Supremo, al gran Creador y Protector del universo. Y ningún ciudadano será perjudicado, molestado o impedido, en su persona, libertad o bienes, por rendir culto a Dios en la manera y momento más conformes con su propia conciencia o según su confesión o sentimientos religiosos siempre que no altere la paz pública o impida el culto religioso de otros $\rangle^{40}$.

Como punto intermedio entre los dos grandes grupos de protección de la libertad religiosa se encuentra el Estado de Georgia que en su Constitución de 1789 estableció la libertad religiosa sólo para los fieles, aunque no recoge la obligación de pagar un impuesto ni financiar ninguna confesión. Por tanto, podríamos decir que los límites de la separación Iglesia/Estado se encuentran más definidos que en los ejemplos anteriores, aunque esta separación no resulte perfecta debido al propio alcance de la mencionada libertad religiosa.

Finalmente se encuentran aquellos territorios que protegían la libertad religiosa de manera universal. En muchos de estos Estados se proclamó expresamente la libertad de conciencia unida a la religiosa. En esta misma línea se planteó la separación Iglesia/Estado, basada en el principio de igualdad con respecto a todas las confesiones que podían existir y ejercitarse ${ }^{41}$.

39 Es el caso del Estado de Maryland en su Declaración de Derechos de la Constitución de Maryland (1776), Massachusetts en su Constitución (1780) y New Hampshire en su Constitución (1784).

40 Traducción consultada en http://ocw.uc3m.es/historia-del-derecho/historia-delconstitucionalismo-americano/otros-recursos-2/tema-2-las-constituciones-revolucionarias/constitucion-de-la-comunidad-de-massachusetts-2013-1780-fragmentos/view

${ }^{41}$ En esta línea se encuentran el Estado de Carolina del Norte con su Constitución de 1776, Pennsylvania con su Declaración de derechos de 1776, New Jersey con su Consti- 
Esta separación se observa en la prohibición de la imposición obligatoria de pagar una tasa a las confesiones religiosa, porque en muchos casos se establecía que no habría Iglesia oficial en el estado. Además, aquellas personas que no fueran protestantes podían ejercer cargos civiles o públicos (Thorpe, 1909, 2788-3090). Esta cuestión está revestida de una gran importancia ya que durante muchos años, en la Metrópoli, las personas podían ser discriminadas en razón a sus creencias religiosas para ejercer cargos en la Administración Pública. Ejemplo de ello es el Act of Settlement (1701) que prohibía que los católicos pudieran ser reyes de Inglaterra e incluso que ostentaran cualquier cargo público. Dicha ley no fue eliminada hasta el siglo XIX (Maurois, 2015, 337-355). Por ello, para los Estados americanos mencionados en este párrafo, era sustancial la concepción de la estricta separación del espacio político y el de la fe para conseguir la libertad y la igualdad. Un ejemplo de ello es el artículo 38 de la Constitución de Nueva York de 1777 que decía que «estamos obligados, como consecuencia del principio de libertad racional, no sólo a expulsar a la tiranía civil, sino también a configurarnos como los guardianes y los defensores contra la opresión espiritual y la intolerancia» (Celador Aragón, 2001, 57).

Pero sin duda es la Declaración de Derechos del Buen Pueblo de Virginia, de 12 de junio de 1776, uno de los documentos más destacados de la historia contemporánea en materia de derechos y libertades (Williams, 2004, 150$203)^{42}$. La libertad religiosa se recoge en su artículo XVI: «Que la religión, $o$ las obligaciones que tenemos con nuestro Creador, y la manera de cumplirlas, sólo pueden estar dirigidas por la razón y la convicción, no por la fuerza o la violencia; $y$, por tanto, todos los hombres tienen idéntico derecho al libre ejercicio de la religión, según los dictados de la conciencia; y que es deber mutuo de todos el practicar la indulgencia, el amor y la caridad cristianas $\rangle^{43}$. Este precepto expresa la igualdad de culto y basa la libertad religiosa en la de conciencia. Empero, no indica claramente la prohibición del pago de un impuesto para las Iglesias. Este punto refleja que los límites separación Iglesia/Estado eran más difusos que en otros territorios (Weber y Gilbert, 1981, 10-15).

Tras esta declaración se encuentra la filosofía de Jefferson pero también su influencia directa, ya que a partir de 1769 fue representante de la Cámara de los Ciudadanos de Virginia. Su autoridad hizo que este Estado avanzara con respecto a la proclamación de la libertad religiosa y de la separación

tución de 1776, Delaware también con su Constitución de 1776 y New York que aprobó su Constitución en 1777.

${ }^{42}$ La influencia del pensamiento y de los postulados de Roger Williams se observa en esta Declaración.

${ }^{43}$ Consultado en https://archivos.juridicas.unam.mx/www/bjv/libros/6/2698/21.pdf 
entre la política y la fe pocos años después de la aprobación de su Declaración. Tras varios debates y nuevos documentos ${ }^{44}$, se aprobó The Bill for Establishing Religious Freedom en 1786, también obra de Jefferson. Lo esencial del texto fue que, como explica Oscar Celador, se acabó con la tradición que mantenía que la neutralidad estatal suponía impulsar aquella religión que profesara la gran parte de la ciudadanía. Así, se terminó con la financiación pública de las Iglesias y sus actividades y se estableció el principio de separación Iglesia/Estado. Además se proclamó la libertad religiosa como un derecho inalienable, un derecho individual de carácter universal que se implantaba para todos los ciudadanos, más allá de los propios creyentes (Celador Aragón, 2001, 58-59).

Hay que destacar también la célebre Declaración de Independencia de los Estados Unidos de América, de 4 de julio de 1776. A nivel de derechos proclamaba la universalidad de los mismos. Eso suponía que no tenía una vocación localista sino una vocación mucho más amplia, aunque en la práctica $-\mathrm{y}$ esto sucede con los documentos jurídicos de carácter universal que se han estudiado anteriormente- excluyeran a gran parte de la población como las mujeres o los esclavos. De igual modo, se amparaba la configuración inalienable de los derechos y el fundamento de que el gobierno tenía como objetivo garantizar las libertades de las personas. Para que el poder político pudiera garantizar estos derechos individuales se necesitaba la no interferencia de otras instituciones que corrieran el riesgo de quebrar este importante principio, concretamente la no interferencia de las Instituciones religiosas. Si no había separación Iglesia/Estado, ¿cómo era posible que el gobierno garantizara las libertades, y la libertad religiosa, de los individuos? El poder político discurría por caminos distintos a los de la estructura eclesiástica (Jellinek, 2000, 105-114). Y la revolución de las trece colonias consolidó esta idea que se refleja claramente no sólo en la Declaración de Independencia sino también en la Constitución federal aprobada en 1787 y modificada en 1791 para recoger las primeras diez enmiendas (Souto paz y Souto Galván, 2010, 28-29)

Esta Constitución federal tenía que ser ratificada por al menos nueve Estados para que pudiera entrar en vigor (Borden, 1967, 83-111). Ocho

${ }^{44}$ Los debates sobre la libertad religiosa continuaron más allá de la aprobación de esta Declaración como demuestra la propuesta en 1784 del Bill Establishing a Provision for Teachers of the Christian Religion, de corte pro-cristiano y que finalmente no se aprobó; y en 1785, en contraposición al primer documento, Madison planteó sus razonamientos en el Memorial and Remostrance Against Religious Assessments.

${ }^{45}$ En la primera Enmienda se recogen dos cláusulas primordiales en este sentido, la «Establishment Clause» que prohíbe establecer una religión oficial en el Estado, y la «Free Excercise Clause» que proclama el libre ejercicio de la religión. 
meses tardaron en ratificarla el mínimo requerido, y más de dos años en que la llevaran a cabo todos y cada uno de los Estados de EEUU ${ }^{46}$. Unida a esta ratificación sobrevolaba el debate de la declaración de derechos federal. En un principio, los representantes reunidos en la Convención Constitucional, en 1787, no se plantearon realmente la inclusión de un Bill of Rights en la Carta Magna ya que cada Estado tenía su propia declaración y las competencias legislativas de la federación no incluían los derechos y libertades. New Hampshire, New York, Massachusetts, Rhode Island y Carolina del Norte exigieron su inclusión en el ámbito federal para ratificar el texto constitucional.

La defensa de la exclusiva regulación estatal de los derechos se atomizó a través del partido federalista que argumentaba que la Federación poseía una competencia legislativa muy limitada en esta materia. Por su parte, el partido republicano defendió la introducción constitucional de los mismos ya que era necesaria la existencia del Bill constitucional federal para limitar y controlar el poder político en este nivel (Levy, 1986, 107-120). Igualmente defendían que había numerosos Estados que no habían aprobado una declaración propia y que algunas de las regulaciones existentes eran demasiado precarias (Celador Aragón, 2001, 64-65; Terradas, 1990, 21-ss.). Finalmente, el primer Parlamento estadounidense (1789) cumplió la promesa de reformar la Constitución para introducir la famosa Declaración de derechos. James Madison, en representación del primer Gobierno federal la presentó en el Congreso y fue aprobada y ratificada el 15 de diciembre de 1791 en las Diez primeras Enmiendas de la Constitución.

La primera enmienda proclama que «El Congreso no hará ley alguna por la que adopte una religión como oficial del Estado o se prohíba practicarla libremente, o que coarte la libertad de palabra o de imprenta, o el derecho del pueblo para reunirse pacificamente y para pedir al gobierno la reparación de agravios» ${ }^{47}$. Dicho artículo nace del consenso entre las distintas fuerzas políticas parlamentarias que tuvieron que ponerse de acuerdo en el contenido final de la libertad religiosa. En esta redacción hubo dos temas sustanciales que dibujaron el debate planteado en torno a esta libertad. En primer lugar, mantener la separación Iglesia/Estado que ya se había expresado claramente en la Declaración de Independencia de 1776. Por otro lado, la propia conceptualización de la libertad religiosa y la de conciencia. Las libertades de expresión, reunión y prensa incluidas en este precepto se deben a Madison que siempre entendió la importancia de la conexión existente entre ellas (Saldaña, 2006, 259-290; Celador Aragón, 2001, 68-72). Este autor

${ }^{46}$ New Hampshire fue el famoso noveno Estado que ratificó el texto constitucional el 21 de junio de 1788.

${ }^{47}$ Consultado en https://www.archives.gov/espanol/constitucion 
buscaba que la protección de estas libertades no se circunscribiera únicamente a las opiniones sino también a las acciones. Asimismo, concibió a estos derechos inalienables como el pilar donde se asentaba la democracia de los Estados Unidos de América (McConnell, 1989, 1480-1503).

\section{CONCLUSIONES}

El hecho religioso forma parte de la historia constitucional de nuestros Estados de Derecho. Todas las religiones han influido, en mayor o menos medida, en varias de las nociones recogidas en nuestras Cartas Magnas. Sin embargo, algunos acontecimientos como las Reformas protestantes tuvieron una gran relevancia para las sociedades y sus transformaciones a lo largo de varios siglos. Pero estas Reformas no hubieran sido posibles sin el proceso que sufrió el cristianismo en la Edad Media.

Tras la caída del Imperio romano de Occidente comienza una profunda transformación que llevará a Europa hacia la época medieval, donde la vida espiritual ocupa un lugar destacado. Este periodo fue, sin duda, un momento crucial para el progreso del futuro modelo de organización estatal, a pesar de su oscurantismo y su opacidad. O quizás justamente por ello es posible hablar hoy en día de Estados democráticos. Las batallas, las luchas de poder, pero también los diferentes conflictos teóricos y las inquietudes que comenzaron a surgir, sobre todo a partir de la Baja Edad Media, son parte integrante de los cambios que se originaron posteriormente y que prepararon a la sociedad para el cambio religioso que culminó en el siglo $\mathrm{XVI}^{48}$.

Los reformadores buscaban impulsar una metamorfosis en la esfera de la fe, pero también en otros niveles como el social o el político. Sus fundamentos se configuraron desde una óptica espiritual, sin embargo, su concepción de la comunicación directa de los creyentes con Dios se vio reflejada en el individualismo que, más tarde, sería parte de las teorías ilustradas y liberales. Lo mismo sucedió con sus hipótesis basadas en la vida desde una óptica justa como parte inseparable de la esencia humana y no desde la perspectiva de que la justicia se basaba en acciones necesarias para buscar el perdón del «Señor». También sus opiniones sobre cómo se debía ejercer el poder afectaron al marco filosófico y jurídico de la época.

Las teorías protestantes proclamaron la idea de tolerancia y, en consecuencia, la libertad para elegir la fe religiosa a la que unirse sin ser perseguido. Este planteamiento estuvo unido a la ulterior aparición de la libertad de conciencia y religiosa. No era una reflexión completamente nueva ya que el cristianismo primitivo se había hecho eco de ella, no obstante, fue esta la

${ }^{48}$ No se puede entender el Protestantismo sin la Inquisición, el agustinismo, la posición de los Papas en el tablero estratégico europeo, o sin el humanismo y la imprenta. 
oportunidad para que su consolidación. Dicha tolerancia no siempre tuvo el éxito pretendido y en Europa se sucedieron numerosos enfrentamientos bélicos donde el hecho religioso formaba parte del conflicto. La importancia de los postulados ilustrados en la conceptualización de la tolerancia es también esencial para entender después cómo se consolidaron la libertad religiosa e ideológica.

Este credo traspasó las fronteras del viejo continente que quedó dividido entre el norte protestante y el sur católico. La persecución religiosa en Europa fue una de las razones que propulsaron la emigración hacia América del Norte, pertenecientes a Gran Bretaña. Su forma de entender la religión fue también parte sustancial del trayecto que llevó hacia los derechos y libertades. La búsqueda de una vida donde poder ejercer la fe elegida de manera libre se propagó por esta región. Así, numerosas iglesias y cultos aparecieron a lo largo y ancho del territorio, mezclando religión con política y demandas sociales de las personas más desfavorecidas.

No obstante, esta cuestión tampoco tuvo un camino fácil en este lugar del mundo ya que diversas organizaciones religiosas y, en concreto, aquellas derivadas del protestantismo no siempre consagraron su teoría de la tolerancia. Así, lo que predicaban en este sentido no fue parte de sus actuaciones en muchas ocasiones. Tanto en Europa como en América, numerosos cultos fueron perseguidos por las Iglesias protestantes más grandes, como el luteranismo o el puritanismo. Diferentes hechos intransigentes se vivieron a lo largo de los años y de los continentes. Las contradicciones forman parte de los seres humanos, de las sociedades y de las religiones, y los reformadores y sus creencias no se libraron de ellas.

Todo ello fue parte de los antecedentes, junto con la Ilustración y los principios liberales, de la aparición de los derechos y libertades a finales del siglo XVIII (Böckenförde, 1994, 44-63). La libertad religiosa jugó aquí una función principal ya que la demanda constante de tolerancia, libertad religiosa y de culto abrió la senda a que se reconocieran otras libertades como la de pensamiento o la de prensa. Es más, en numerosas declaraciones estadounidenses esta libertad religiosa se recoge en sus primeros artículos. La configuración de esta libertad en América del Norte se basaba en que era un «tipo especial del ejercicio del derecho de libertad ideológica» (Celador Aragón, 2001, 48).

La aparición de las confesiones protestantes tuvo un importante papel en el avance del ámbito teórico y del Derecho, pero sobre todo ayudó a romper con la unidad religiosa medieval. La pluralidad de iglesias y cultos en el cristianismo, que comenzó a partir de su aparición, supuso la imparable marcha hacia la libertad religiosa. Numerosas tesis expuestas por los autores reformadores se unieron a la senda del pensamiento crítico y lo fomentaron. Tanto las acciones de los protestantes y el establecimiento de sus Iglesias, como el desarrollo filosófico de sus reflexiones, contribuyeron a la conformación de 
los principios que sustentan hoy en día nuestras democracias (Peces-Barba, 2001, 23).

\section{BIBLIOGRAFÍA}

Aguilera Barchet, B. (2011). Entre Estado y nación, Paris: Instituto de Estudios Jurídicos Internacionales y Université Paris-Est.

APARISI Miralles. (1990). «La Declaración de Independencia Americana de 1776 y los Derechos del Hombre». Revista de Estudios Políticos, Vol. 70.

Asimov, I. (2012). La formación de América del Norte. Desde los tiempos primitivos hasta 1763. Madrid: Alianza.

Barrero Ortega, A. (2000). «Origen y actuación de la libertad religiosa». Revista del Instituto Bartolomé de las Casas, Año V, julio/diciembre.

BAYLIN, B. (1972). The Ideological Origins of the American Revolutions. Cambridge: Harvard University Press.

BERGER, P. L. (1983). Para una teoría sociológica de la religión. Barcelona: Kairós. Bodino, J. (1997). Los Seis Libros de la República. Madrid: Tecnos.

BÖCKENFÖRDE, E-W. (1994). Escritos sobre derechos fundamentales. Baden-Baden: Nomos Verlagsgesellschaft.

Borden, M. (1967). Parties and Politics in the Early Republic, 1789-1815. Wheeling : Harlan Davison.

Bosch, A. (2011). Historia de Estados Unidos. 1776-1945. Barcelona: Crítica, Barcelona.

CARvajal, P. (2000). «El derecho de resistencia en la teología política de Juan Calvino». Revista de Estudios histórico-jurídicos, $\mathrm{n}^{\circ} 22$, Valparaíso.

- (1992). «Derecho de resistencia, derecho de revolución, desobediencia civil. Una perspectiva histórica de interpretación: la formación del derecho público y de la ciencia política en la temprana Edad Moderna». Revista de Estudios Políti$\cos , \mathrm{n}^{\circ} 76$.

Celador Aragón, O. (2001). «Libertad religiosa y revoluciones ilustradas». En PECES-BARBA MARTINEZ, G., FERNÁNDEZ GARCÍA, E., y DE ASÍS ROIG, R. F. Historia de los derechos fundamentales, Tomo II: Siglo XVIII, Volumen II, la filosofía de los derechos humanos. Madrid: Dykinson, Madrid.

- (1998). El Estatuto Jurídico de las Confesiones religiosas en el Ordenamiento Jurídico estadounidense. Madrid: Dykinson.

De Tocqueville, A. (1978). La democracia en América. México-Buenos Aires: Fondo de Cultura Económica.

Duby, G. (2007). Europa en la Edad Media. Barcelona: Paidós.

Edelmayer, F. (2001). «Carlos V y la quiebra del humanismo político en Europea (1530-1558)». En MARTÍNEZ MILLAR, J. (coord.). Congreso internacional, Madrid 3-6 de julio de 2000. Vol. 1. Madrid: Sociedad Estatal para la conmemoración de los centenarios de Felipe II y Carlos V.

Filoramo, G., Massenzio, M., RAVERI, M., y Scarpi, P. (2012). Historia de las religiones. Barcelona: Crítica.

— (1993). Diccionario de las Religiones. Madrid: AKAL. 
Flavel, J. (2018). El misterio de la Providencia. La manera de obrar de Dios, Teología para Vivir. Clásicos Reformados.

GaArder, J., Hellern, V., y Notaker, H. (2016). El libro de las religiones. Madrid: Siruela.

GARCÍA Portela, L. (2014). «La Revolución Americana: una revuelta desde y contra Inglaterra. Un ensayo sobre sus orígenes ideológicos». Revista Historia Autóno$m a, \mathrm{n}^{\circ} 5$.

García Trujillo, M. B. (1997). «El modelo americano de protección de los derechos fundamentales: primeras formulaciones». Anuario de la Facultad de Derecho, número 19, Universidad de Extremadura.

GonzÁlez Díez, E (dir.) y GonzÁlez Hernández, E. (2018). Las Cortes de León: cuna del parlamentarismo. Madrid: Centro de Estudios Políticos y Constitucionales.

HANCOCK, R. (1989). Calvino and the foundations of modern politics. Ithaca: Cornell University Press.

Harding, A. (1993). England in the Thirteenth Century. Cambridge : Cambridge University Press.

HobBes, T. (2014). Leviatán. O la materia, forma y poder de un Estado eclesiástico y civil. Madrid: Alianza Editorial.

Holmes, G. (1986). Politics, Religion and Society in England. 1679-1742. London: The Hambledon Press.

James, S. V. (1999). John Clarke and his Legacies. Religion and Law in Colonial Rhode Island 1638-1750. Pennsylvania : Penn State University Press.

JEFFERSON, T. (2014). Escritos politicos: declaración de independencia, autobiografía, epistolario. Madrid: Tecnos.

Jellinek, G. (2000). La Declaración de los Derechos del Hombre y del Ciudadano. México: Universidad Nacional Autónoma de México.

Kamen, H. (1987). Alianza y desarrollo en la Europa moderna. Madrid: Alianza Editorial.

Letocha, D. (2005). «La autoridad de la conciencia ante el Concilio de Trento». Ideas y Valores, vol. 54, núm. 127, abril.

Levy, L. (1986). Constitutional Opinions. Aspects of the Bill of Rights. Oxford: Oxford University Press.

Locke, J. (1999). Escritos sobre la tolerancia. Madrid: Centro de Estudios Políticos y Constitucionales.

Madison, J. (2005). República y libertad. Madrid: Centro de Estudios Políticos y Constitucionales, Madrid, 2005.

MÁrquez CARrasco, C. (2010), «Reforma, capitalismo y estados modernos en la Europa anterior a Westfalia». En SUÁREZ VILLLEGAS, J C. (ed.), Reforma protestante y libertades en Europa, Madrid: Dykinson.

Maurois, A. (2015). Historia de Inglaterra. Barcelona: Ariel Historia.

MCCONNELl, M. W. (1989). «The Origins and Historical Understanding of Free Exercise of Religion». Harvard Law Review, Vol. 103.

Mitre, E. (2010). «Descomposición del orden romano (siglo IV). El cristianismo». En ClARAMUNT, S, PORTELA. E, GONZÁlEZ. M, y MiTRE. E. (2010). Historia de la Edad Media. Barcelona: Ariel Historia. 
Mora Mérida, J. L. (1992). Iglesia y Religión en los Estados Unidos y Canadá. Madrid: Mapfre.

Ortega y Medina, J. A. (2013). La evangelización puritana en Norteamérica. Delendi sunt indi. México: Universidad Autónoma de México. Instituto de Investigaciones Históricas.

Peces-Barba Martínez, G. (1989). «Algunas reflexiones sobre la libertad ideológica y religiosa». IBÁN PÉREZ, C., (coord.). Libertad y derecho fundamental de libertad religiosa (Arcos de la Frontera, 1 y 2 de febrero de 1989), Madrid: Editoriales de Derecho Reunidas EDERSA.

- (1993). Derecho y Derechos Fundamentales. Madrid: Centro de Estudios Políticos y Constitucionales.

Pesch, O. H. (2002). «La respuesta del Concilio de Trento: 1545-1563». Selecciones de teología, $\mathrm{n}^{\mathrm{o}} 164$.

RIVERA GARCÍA, A. (2010). «El pensamiento jurídico-político de Calvino y el moderno Estado de derecho». SUAREZ VILLLEGAS, J C. (ed.), Reforma protestante y libertades en Europa, Madrid: Dykinson.

Russell, B. (2010). Historia de la Filosofia Occidental, Tomo II. Madrid: Espasa libros.

SALDAÑA, M. N. (2006). «La gestación de la primera enmienda: «founding period» $y$ «original meaning»». Historia Constitucional, $\mathrm{n}^{\mathrm{o}} 7$.

Satústregui Gil-Delgado, M. (2009). «La Magna Carta: realidad y mito del constitucionalismo pactista medieval». Historia Constitucional, $\mathrm{n}^{\mathrm{o}} 10$.

Souto Paz, J. A, y Souto Galván, C. (2010). El derecho de libertad de creencias. Madrid: Marcial Pons, Madrid.

SuÁREZ Villlegas, J. C. (2010). «Teología y política en la reforma protestante». En SUÁREZ VILLLEGAS, J C. (ed.), Reforma protestante y libertades en Europa, Madrid: Dykinson.

TEJA, R. (2006). «El poder de la Iglesia Imperial: el mito de Constantino y el Papado romano». Studia Historica. Historia antigua, $\mathrm{n}^{\circ} 24$.

Terradas, I. (1990). Revolución y Religiosidad. Valencia: Alfons el Magnánim.

Thorpe, F. (1909). The Federal and State Constitutions, Colonial Charters, and other Organic Laws. Washington: Government Printing Office.

Toscano Franca FilHo, M. (2006). «Historia y razón del paradigma Westafaliano». Revista de Estudios Políticos, núm. 131, enero-marzo.

Troeltsch, E. (1958). El protestantismo y el mundo moderno. México: Fondo de Cultura Económica.

VÁzQuez Gómez, R. (2009). «El poder político y la religión en el puritanismo: la Colonia americana de la Bahía de Massachusetts». Revista Española de Derecho Constitucional, núm. 86, mayo-agosto.

Voltaire (2013). Tratado sobre la tolerancia. Barcelona: Austral.

Weber, P, y Gilbert, D. (1981). Private Churches and Public Money. Connecticut: Greenwood Press.

WickHAm, C. (2007). Europa en la Edad Media. Barcelona: Crítica.

WiLliAms, R. (2004). El sangriento dogma de la persecución por causa de conciencia. Madrid: Centro de Estudios Políticos y Constitucionales.

WyCLIF, J. (1382), Triálogo entre la Verdad, la Mentira y la Prudencia (Trialogus). 


\title{
LA CONTRIBUCIÓN DE LAS REFORMAS PROTESTANTES EN LA APARICIÓN DE LOS DERECHOS Y LIBERTADES
}

\author{
The protestant reform's contribution on the appearance of \\ rights and freedoms
}

\author{
Cecilia Rosado-Villaverde \\ Profesora Contratada Doctora de Derecho Constitucional \\ Universidad Rey Juan Carlos
}

http://dx.doi.org/10.18543/ed-69(1)-2021pp241-277

\section{Copyright}

Estudios de Deusto es una revista de acceso abierto, lo que significa que es de libre acceso en su integridad. Se permite su lectura, la búsqueda, descarga, distribución y reutilización legal en cualquier tipo de soporte sólo para fines no comerciales, sin la previa autorización del editor o el autor, siempre que la obra original sea debidamente citada y cualquier cambio en el original esté claramente indicado

Estudios de Deusto is an Open Access journal which means that it is free for full access, reading, search, download, distribution, and lawful reuse in any medium only for non-commercial purposes, without prior permission from the Publisher or the author; provided the original work is properly cited and any changes to the original are clearly indicated. 